\title{
Production Planning of a Failure-Prone Manufacturing System under Different Setup Scenarios
}

\author{
Guy-Richard Kibouka, ${ }^{1}$ Donatien Nganga-Kouya, ${ }^{1}$ Jean-Pierre Kenne, ${ }^{2}$ \\ Victor Songmene, ${ }^{2}$ and Vladimir Polotski ${ }^{2}$ \\ ${ }^{1}$ Mechanical Engineering Department, Omar Bongo University, École Normale Supérieure de l'Enseignement Technique, \\ BP 3989, Libreville, Gabon \\ ${ }^{2}$ Mechanical Engineering Department, University of Quebec, École de Technologie Supérieure, 1100 Notre Dame West, \\ Montreal, QC, Canada H3C 1 K3
}

Correspondence should be addressed to Jean-Pierre Kenne; jean-pierre.kenne@etsmtl.ca

Received 10 November 2015; Accepted 17 December 2015

Academic Editor: Dar-Li Yang

Copyright (C) 2016 Guy-Richard Kibouka et al. This is an open access article distributed under the Creative Commons Attribution License, which permits unrestricted use, distribution, and reproduction in any medium, provided the original work is properly cited.

This paper presents a control problem for the optimization of the production and setup activities of an industrial system operating in an uncertain environment. This system is subject to random disturbances (breakdowns and repairs). These disturbances can engender stock shortages. The considered industrial system represents a well-known production context in industry and consists of a machine producing two types of products. In order to switch production from one product type to another, a time factor and a reconfiguration cost for the machine are associated with the setup activities. The parts production rates and the setup strategies are the decision variables which influence the inventory and the capacity of the system. The objective of the study is to find the production and setup policies which minimize the setup and inventory costs, as well as those associated with shortages. A modeling approach based on stochastic optimal control theory and a numerical algorithm used to solve the obtained optimality conditions are presented. The contribution of the paper, for industrial systems not studied in the literature, is illustrated through a numerical example and a comparative study.

\section{Introduction}

The production and setup planning problem surfaces in manufacturing systems when significant cost and time are required to set up the production unit for the processing of multiple part types. The setup scheduling problem involves deciding which part type has to be processed next and when the production unit has to stop its current operations and make a setup change to begin the processing of that part type. The time required to switch from producing one part type to another and the associated cost are significant. Given that it is not realistic (or advantageous) to devote one machine to a single part type, different part types must share the same machine, and capacity is lost due to each setup change. In addition, the considered machine is subject to random breakdowns and repairs. It is therefore essential to jointly investigate setup scheduling and production policies in order to optimize the system performance measure of the failureprone manufacturing system under study.

For the class of completely flexible machines (based on a crucial assumption that no setup time and cost are required when production is switched from one part type to another), an explicit formulation of the optimal control problem for an unreliable flexible machine which produces multiple part types is provided in [1]. In addition, Gharbi and Kenné [2] provided a suboptimal control policy for the multiple parts, multiple-machines problem. The considered planning problem falls under an important class of stochastic manufacturing systems involving nonflexible machines, given that the setup time and costs are considered when production is switched from one product type to another. This class of systems is a subset of manufacturing systems for which the problem of determining the optimal production policies has been considered by many authors. A significant portion of 
the research by the latter is based on a feedback formulation of the control problem in a dynamic manufacturing environment. It is shown in [3] that the optimal control policy has a special structure called the Hedging Point Policy (HPP) in the case of a single-machine, single product system. For such a policy, a nonnegative production surplus of parts, corresponding to optimal inventory levels, is maintained during times of excess capacity in order to hedge against future capacity shortages caused by machine failures for the case of a single-machine, two-product manufacturing system with setup (see [4]). Various researchers have considered the problems of setup scheduling in production using advanced optimization approaches in the context of multiple-product manufacturing systems. As recently stated in [5], the problems of sequence-dependent setup times have been attracting increasing interest [6]. Previous sequence-dependent setup times are studied using objective functions such as makespan, total completion time, and their combinations, with an emphasis on the learning aspects of the sorting algorithms. In the same context, Feng et al. [7] optimized various scheduling policies and then analyzed them from the point of view of their robustness to uncertainties and system parameter variations. The obtained setup policy had a cyclic policy structure resilient to parameter variations.

The stochastic optimal control problem of a manufacturing system with setup costs and time was formally presented in [4] following the series of papers published in the same domain by Sethi and Zhang [8], Yan and Zhang [9], Boukas and Kenné [10] and Hajji et al. [11]. The proposed models led to the optimality conditions described by the Hamilton Jacobi Bellman equations (HJB). Such equations are difficult to resolve analytically for more general cases. An explicit solution for such equations was obtained by Akella and Kumar [12] for a one-machine, one-product manufacturing system. Numerical methods based on the Kushner approach (see Kushner and Dupuis [13]) were used by Yan and Zhang [9] and Boukas and Kenné [10] for a one-machine, two-product manufacturing system. They were able to develop nearoptimal control policies for production and setup scheduling in the case of a homogeneous and machine age-dependent Markovian process.

For the one-machine, two products' case, Yan and Zhang [9] provide a characterization of the optimal production and setup policy by four exclusive regions as a main result, while Bai and Elhafsi [14] focused their contribution on providing a suitable production and setup policy structure and obtained the so-called Hedging Corridor Policy (HCP). Following these studies, Gharbi et al. [4] developed a production and setup policy for unreliable multiple-machine, multiple part type manufacturing system, for which the production and setup policy are known across the sample space. They obtained a control policy called the Modified Hedging Corridor Policy (MHCP), qualified as more realistic and useful in the context of the production planning of manufacturing systems with setup.

The main contribution of this paper is to develop a production and setup policy for a more realistic unreliable one-machine, one-part type manufacturing system under appropriate assumptions in different industrial situations, called here industrial scenarios. The resultant control policy is more realistic and useful in the context of the production planning of manufacturing systems with setup. This paper's contribution is further illustrated through the fact that the proposed control policy guarantees a system performance for systems that have not yet been studied in the relevant literature. Our proposal is an extension of the works of Bai and Elhafsi [14], Boukas and Kenné [10], and Hajji et al. [11].

This paper is organized as follows: Section 2 presents the notations and main assumptions of the proposed model. Section 3 presents the statement of the optimal production and setup scheduling problem. The optimality conditions and numerical approach are presented in Section 4. Section 5 describes the numerical example with results analysis, and the paper is concluded in Section 6.

\section{Model Assumptions and Hypotheses}

This section presents the notations and assumptions used throughout this paper.

\subsection{Notations}

$$
\begin{aligned}
& P_{i}: \text { part type } i(i \in I=\{1,2\}), \\
& \theta_{i j}: \text { setup time to go from } P_{i} \text { to } P_{j}, \\
& K_{i j}: \text { setup cost to go from } P_{i} \text { to } P_{j}, \\
& d_{i}: \text { rate of } P_{i} \text { product request, } \\
& x(t) \text { : vector inventory levels/shortage, product type } i, \\
& p_{i}: \text { product processing time, type } i, \\
& u_{i}(t): \text { production rate, product type } i, \\
& U_{i}^{+}: \text {maximum production rate, product type } i, \\
& z_{i}: \text { optimal inventory level, product type } i, \\
& \alpha(t): \text { stochastic process describing the dynamics of } \\
& \text { the machine, } \\
& S_{i j}: \text { setup policy from product part type } i \text { to } j, \\
& q_{\alpha \beta}: \text { transition rate, mode } \alpha \beta, \\
& c_{i}^{-}: \text {shortage cost, product type } i, \\
& c_{i}^{+}: \text {inventory cost, product type } i, \\
& \rho: \text { cost discount rate, } \\
& g(\cdot): \text { cost function, } \\
& R(\cdot): \text { total cost function during setup, } \\
& J(\cdot): \text { total cost function, } \\
& v(\cdot): \text { value function. }
\end{aligned}
$$

2.2. Context and Assumptions. The following is a summary of the general context and main assumptions considered in this paper:

(1) The model is time-continuous.

(2) Raw materials for the production of each product part type are always available and unlimited. 


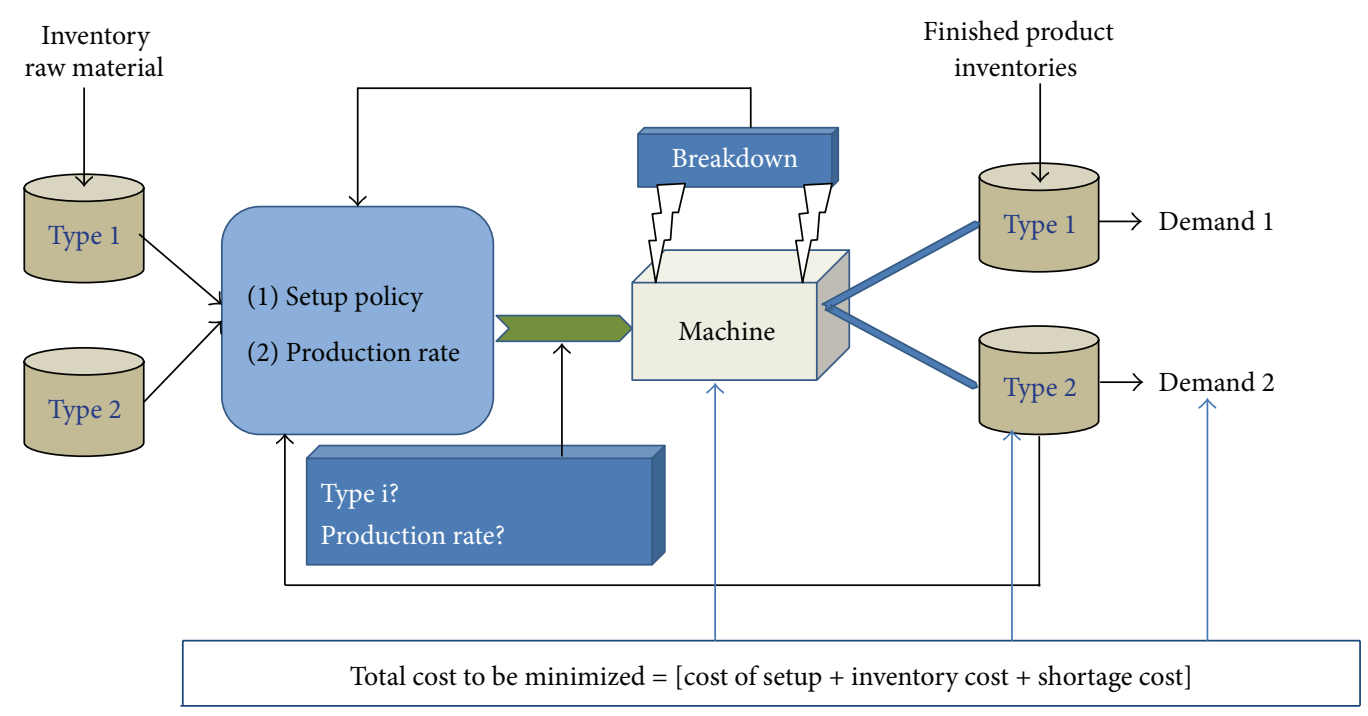

FIGURE 1: Manufacturing system studied.

(3) Customer demand of finished products for each part type is known and represented by a constant rate over time.

(4) The maximal production rate of each part type is known.

(5) All failures are instantly detected and repaired. A corrective maintenance action renews the production system to its initial state (as good as new condition).

(6) The machine shares the production of different product part types with significant setup time and cost.

(7) The shortage cost depends on the shortage quantity and time (average value (\$/product/unit of time)).

(8) The holding cost depends on the mean inventory level (average value (\$/product/unit of time)).

(9) For each product part type, once the production starts at a given rate, no adjustment of the rate will be allowed until either the machine is down (failure mode) or the current unit is completed.

We complete the assumptions by two hypotheses that help us to study different industrial contexts (or production scenarios) with setup.

Hypothesis 1. The setup operation is performed only when the machine is in operational mode and cannot be interrupted by any machine failure such that it has to be started all over again.

Hypothesis 2. The setup operation is only allowed if the machine is in operational mode, and the setup process is interrupted by failure such that it can be continued after a repair.

In this paper, we show how the hypotheses affect the optimality conditions of the associated stochastic optimal control problem. We then develop appropriate optimality conditions consisting of a modified form of the traditional
HJB equations. We finally compare the results obtained for the two hypotheses (or contexts of production) in order to provide more realistic production and setup policies.

\section{Problem Formulation}

The production system presented in Figure 1 consists of one machine capable of producing two different part types. The machine is not completely flexible in the sense that the setup activities between the two part types involve both time and cost to switch from the production of one part type to another. The system under study is dynamic and the associated costs to be minimized are illustrated in Figure 1.

Let $\theta_{i j}$ and $K_{i j}$ be the duration and the cost incurred for switching the production from $P_{i}$ to $P_{j}$ with $i \neq j$, respectively. Note that, for $i, j=1,2$ and $i \neq j, \theta_{i j} \geq 0$ and $K_{i j} \geq 0$.

The $i$-type product requires an average production time denoted as $p_{i}>0(i=1,2)$ and ordered with a constant demand rate $d_{i}$.

Let $x_{i}(t), u_{i}(t)$ be the stock level and the rate of production of two part types of products $P_{i}, i=1,2$, respectively.

Let $\mathbf{x}, \mathbf{u}$, and $\mathbf{d}$ denote the vectors $\left(x_{1}, x_{2}\right)^{t},\left(u_{1}, u_{2}\right)^{t}$, and $\left(d_{1}, d_{2}\right)^{t}$, respectively, knowing that the notation $A^{t}$ denotes the transpose of $A$.

At a given moment, we can describe the system by a hybrid state that consists of a continuous portion (stock dynamics) and a discrete portion (modes of the machine). A stochastic process $\xi(t)$ is used to describe the mode of the machine as follows:

$$
\xi(t)= \begin{cases}1 & \text { if the machine is operational } \\ 2 & \text { if the machine is under repair. }\end{cases}
$$

The machine uptimes and downtimes are assumed to be exponentially distributed with rates $p$ and $q$, respectively. Hence, the machine state evolves according to a continuoustime Markov process with modes $\xi(t) \in M=\{1,2\}$. The states 


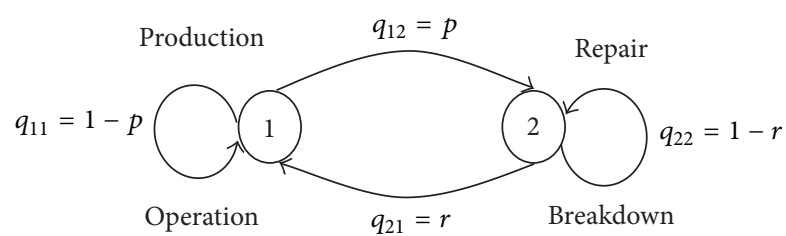

Figure 2: States transition diagram of the system studied.

transition diagram of the Markov chain associated with the machine dynamics is shown in Figure 2.

The evolution of machine states in the interval $(t, t+\delta t)$ can be expressed by

$$
\begin{aligned}
& \operatorname{prob}(\xi(t+\delta t)=1 \mid \xi(t)=2)=q_{12} \delta t+0(\delta t), \\
& \operatorname{prob}(\xi(t+\delta t)=1 \mid \xi(t)=1)=1+q_{12} \delta t+0(\delta t), \\
& \operatorname{prob}(\xi(t+\delta t)=2 \mid \xi(t)=1)=q_{21} \delta t+0(\delta t), \\
& \operatorname{prob}(\xi(t+\delta t)=2 \mid \xi(t)=2)=1+q_{21} \delta t+0(\delta t) .
\end{aligned}
$$

The process $\xi(t)$ can be described by a transition rate matrix $Q=\left\{q_{\alpha \beta}\right\}$, defined by $q_{\alpha \beta} \geq 0$ si $\alpha \neq \beta$ and $q_{\alpha \alpha}=-\sum_{\alpha \neq \beta} q_{\alpha \beta}$, knowing that $\alpha, \beta \in M$.

The transition rate from a state $\alpha \in M$ to a state $\beta \in M$ at time $t$ is defined by

$$
\begin{array}{r}
q_{\alpha \beta}=\lim _{\delta t \rightarrow 0}\left[\operatorname{prob} \frac{(\xi(t+\delta t)=\beta \mid \xi(t)=\alpha)}{\delta t}\right], \\
\alpha \neq \beta \text { knowing that } \lim _{\delta t \rightarrow 0} \frac{0(\delta t)}{\delta t}=0 .
\end{array}
$$

The corresponding matrix of transition rates $e$ is given in the following:

$$
Q=\left(\begin{array}{cc}
-q_{12} & q_{12} \\
q_{21} & -q_{21}
\end{array}\right)
$$

The differential equation representing the dynamics of the finished products stocks is

$$
\begin{aligned}
& \dot{x}(t)=\frac{d x(t)}{d t}=u(t)-d, \\
& x(0)=x_{0},
\end{aligned}
$$

where $x_{0}$ is the initial stock level.

The production rates satisfy the system capacity constraint given by the following equation:

$$
0 \leq u_{i}(\cdot) \leq \grave{U}_{i}^{+}, \quad i=1,2
$$

where $\grave{U}_{i}^{+}$denotes the maximal production rate of product $i$ on the machine. The set of feasible production rates of the machine for a product $i$ is given by

$$
\Gamma(\alpha)=\left\{u: u=\left(u_{1}, u_{2}\right), 0 \leq u_{i}(\cdot) \leq \grave{U}_{i}^{+}, i=1,2\right\} .
$$

The decision variables of the optimal control problem under study are production rates $u=\left(u_{1}, u_{2}\right)$ and a sequence of setups denoted by $\Omega=\left\{\left(\tau_{0}, i_{0} i_{1}\right),\left(\tau_{1}, i_{1} i_{2}\right), \ldots\right\}$. A setup $(\tau, i j)$ is defined by the time $\tau$ at which it begins and a pair $i j$, denoting that the system was already set up to produce part $i$, and is being switched to be able to produce part $j$. Let $A$ denote the set of admissible decisions $\left(\Omega, u_{1}, u_{2}\right)$.

The instantaneous cost function depends on the state of the system (stock level, mode of the machine) and is given by

$$
g(x, \alpha)=\left(c_{1}^{+} x_{1}^{+}+c_{1}^{-} x_{1}^{-}+c_{2}^{+} x_{2}^{+}+c_{2}^{-} x_{2}^{-}\right)+c^{\alpha},
$$

where $c^{\alpha}$ is the cost incurred at mode $\alpha$ of the machine (assuming that $c^{1}=0$ and $\left.c^{2} \neq 0\right)$. Note that $x_{i}^{+}=\max \left(0, x_{i}\right)$ and $x_{i}^{-}=\max \left(-x_{i}, 0\right) ; c_{i}^{+}$and $c_{i}^{-}$are inventory and backlog costs for part type $i$ per unit of product per unit of time, respectively.

Given that the setup cost is consumed at the beginning of the operation, the instantaneous cost as a function of the setups denoted as $R(\cdot)$ is therefore expressed by the following expression:

$$
\begin{array}{r}
R_{i j}(x, s)=K_{i j} \text { Ind }\left\{s=\Theta_{i j}\right\}+\int_{0}^{s} e^{-\rho t} g(x-d) d t, \\
s \in\left[0, \Theta_{i j}\right], i, j=1,2, i \neq j,
\end{array}
$$

where $\rho$ is the discount rate. The first part of (9) expresses the setup cost at the beginning of the operation. The second part evaluates the penalty incurred for an inventory during the setup, depending on the time remaining in the setup operation, denoted as $s$, with

$$
\text { Ind }\left(s=\Theta_{i j}\right)= \begin{cases}1 & \text { if } s=\Theta_{i j} \\ 0 & \text { otherwise. }\end{cases}
$$

We can deduce the instantaneous cost function of the setup as follows:

$$
\begin{aligned}
R_{12}\left(x, \Theta_{12}\right)= & K_{12} \\
& +\int_{0}^{\Theta_{12}} e^{-\rho t} g\left(x_{1}-d_{1} t ; x_{2}-d_{2} t\right) d t \\
R_{21}\left(x, \Theta_{21}\right)= & K_{21} \\
& +\int_{0}^{\Theta_{21}} e^{-\rho t} g\left(x_{1}-d_{1} t ; x_{2}-d_{2} t\right) d t .
\end{aligned}
$$

The total discounted cost over an infinite horizon can then be defined by the following expression:

$$
\begin{aligned}
& J(i, x, \alpha, s, \Omega, u(\cdot)) \\
& =\int_{0}^{s} e^{-\rho t} g(x(t)) d t \\
& \quad+E_{i, x-d s, \alpha_{s}}\left[\int_{s}^{\infty} e^{-\rho t} g(x(t)) d t+\sum_{i=0}^{\infty} e^{-\rho \tau_{i}} K_{i_{1} i_{1+1}}\right] .
\end{aligned}
$$


The production planning problem is to find an admissible decision or control policy $(\Omega, u(\cdot))$ that minimizes $J(\cdot)$, given by (12). For the production of part type $i$, the value function can be given by the following:

$$
v_{i}(x, \alpha, s)=\min _{(\Omega, u) \in A} J(i, x, \alpha, s, \Omega, u)
$$

$\forall x \in R^{n}, \alpha \in M$.

In the next section, we present the optimality conditions and the corresponding discrete form obtained by the application of the numerical methods inspired from the Kushner approach (see [11] for more details).

\section{Optimality Conditions and Numerical Approach}

In this section, we present the modified $\mathrm{HJB}$ equations related to Hypotheses 1 and 2. We then compare the results obtained for those hypotheses to the results given by the application of the traditional form used in Yan and Zhang [9], Bourkas and Kenné [10], and Hajji et al. [11].

The value function $v_{i}(x, \alpha)$ that satisfies the HJB equations in mode 1 for Hypothesis 1 is

$$
\begin{aligned}
& \min \left\{\min _{u \in \Gamma_{i}(\alpha)}\left[(u-d)\left(v_{i}\right)_{x}(x, \alpha)+g(x)+Q v_{i}(x, \cdot)(\alpha)\right]\right. \\
& \left.-\rho v_{i}(x, \alpha) ; \min _{j \neq i}\left[R_{i j}\left(x, \Theta_{i j}\right)+\left(P_{i j}\right) e^{-\rho \Theta_{i j}} \cdot v_{j}\left(x-d \Theta_{i j}, 1\right)+\left(1-P_{i j}\right) e^{-\rho \Theta_{i j}} \cdot v_{j}\left(x-d \tau_{i j}, 1\right)\right]-v_{i}(x, \alpha)\right\}=0 .
\end{aligned}
$$

The value function $v_{i}(x, \alpha)$ that satisfies HJB equations in mode 1 for Hypothesis 2 is

$$
\begin{aligned}
& \min \left\{\min _{u \in \Gamma_{i}(\alpha)}\left[(u-d)\left(v_{i}\right)_{x}(x, \alpha)+g(x)+Q v_{i}(x, \cdot)(\alpha)\right]\right. \\
& -\rho v_{i}(x, \alpha) \\
& \left.\min _{j \neq i}\left[R_{i j}\left(x, \widehat{\Theta_{i j}}\right)+e^{-\rho \widehat{\Theta_{i j}}} \cdot v_{j}\left(x-d \widehat{\Theta_{i j}}, 1\right)\right]\right\}=0,
\end{aligned}
$$

where $\left(v_{i}\right)_{x}(\cdot)$ is the gradient of $v_{i}(\cdot)$ related to $x$. Moreover,

$$
Q v_{i}(x, \cdot)(\alpha)=\sum_{\alpha \neq \beta} q_{\alpha \beta}\left(v_{i}(x, \beta)-v_{i}(x, \alpha)\right) \text {. }
$$

Let $S_{i}(\alpha)$ be the machine configuration changes (setup) defined by the following: (a) for Hypothesis 1,

$$
\begin{gathered}
S_{i}(\alpha)=\left\{x: \min _{j \neq i}\left[R_{i j}\left(x, \Theta_{i j}\right)+\left(P_{i j}\right) e^{-\rho \Theta_{i j}}\right.\right. \\
\cdot v_{j}\left(x-d \Theta_{i j}, 1\right)+\left(1-P_{i j}\right) e^{-\rho \Theta_{i j}} \\
\left.\left.\cdot v_{j}\left(x-d \tau_{i j}, 1\right)\right]=v_{i}(x, \alpha)\right\} ;
\end{gathered}
$$

(b) for Hypothesis 2,

$$
\begin{aligned}
S_{i}( & \alpha) \\
& =\left\{x: \min _{j \neq i}\left[R_{i j}\left(x, \widehat{\Theta_{i j}}\right)+e^{-\rho \widehat{\Theta_{i j}}} \cdot v_{j}\left(x-d \widehat{\Theta_{i j}}, 1\right)\right]\right. \\
& \left.=v_{i}(x, \alpha)\right\} .
\end{aligned}
$$

Let us use the Kushner approach method (Kushner and Dupuis [13]), as in [16], to develop the numerical form of HJB equations. The basic idea behind it consists in using an approximation scheme for the gradient of the value function. Let $h_{j}, j=1,2$, denote the length of the finite difference interval of the variable $x_{j}$. Using the finite difference approximation, $v(x, \alpha)$ could be given by $v_{i}^{h}(x, \alpha)$ and $\left(v_{i}\right)_{x j}(x, \alpha)$ by

$$
\left(v_{i}\right)_{x j}(x, \alpha)= \begin{cases}\frac{1}{h_{j}}\left(v_{i}^{h}\left(x_{1}, \ldots, x_{j}+h_{j}, \ldots, x_{2}\right)-v_{i}^{h}\left(x_{1}, \ldots, x_{j}, \ldots, x_{2}\right)\right) & \text { if } u_{j}-d_{j} \geq 0 \\ \frac{1}{h_{j}}\left(v_{i}^{h}\left(x_{1}, \ldots, x_{j}, \ldots, x_{2}\right)-v_{i}^{h}\left(x_{1}, \ldots, x_{j}-h_{j}, \ldots, x_{2}\right)\right) & \text { if } u_{j}-d_{j}<0 .\end{cases}
$$


The following expression can be deduced:

$$
\begin{aligned}
& \left(u_{j}-d_{j}\right)\left(v_{i}\right)_{x j}(x, \alpha)=\frac{\left|u_{j}-d_{j}\right|}{h_{j}} \\
& \cdot v_{i}^{h}\left(x_{1}, \ldots, x_{j}+h_{j}, \ldots, x_{2}\right) \text { Ind }\left\{u_{j}-d_{j} \geq 0\right\} \\
& +\frac{\left|u_{j}-d_{j}\right|}{h_{j}} v_{i}^{h}\left(x_{1}, \ldots, x_{j}-h_{j}, \ldots, x_{2}\right)
\end{aligned}
$$

$$
\begin{aligned}
& \cdot \text { Ind }\left\{u_{j}-d_{j}<0\right\}-\frac{\left|u_{j}-d_{j}\right|}{h_{j}} \\
& \cdot v_{i}^{h}\left(x_{1}, \ldots, x_{j}, \ldots, x_{2}\right) .
\end{aligned}
$$

Following the previous approximation, we can express (14) and (15) in terms of $v_{i}^{h}(x, \alpha)$ as follows:

(a) for Hypothesis 1,

$$
\begin{aligned}
& v_{i}^{h}(x, \alpha) \\
& \quad=\min \left\{\min _{u \in \Gamma_{i}(\alpha)}\left\{\left(\rho+\left|q_{\alpha \alpha}\right|+\sum_{j=1}^{2} \frac{\left|u_{j}-d_{j}\right|}{h_{j}}\right)^{-1}\left[\sum_{j=1}^{2} \frac{\left|u_{j}-d_{j}\right|}{h_{j}} v_{i}^{h}\left(x\left(h_{j},+\right) \operatorname{Ind}\left(u_{j}-d_{j} \geq 0\right)+v_{i}^{h}\left(x\left(h_{j},-\right)\right) \operatorname{Ind}\left(u_{j}-d_{j}<0\right)\right)+g(x)+\sum_{\beta \neq \alpha} q_{\alpha \beta} * v_{i}^{h}(x, \beta)\right]\right\} ;\right. \\
& \left.\quad \min _{j \neq i}\left[R_{i j}\left(x, \Theta_{i j}\right)+\left(P_{i j}\right) e^{-\rho \Theta_{i j}} \cdot v_{j}\left(x-d \Theta_{i j}, 1\right)+\left(1-P_{i j}\right) e^{-\rho \Theta_{i j}} \cdot v_{j}\left(x-d \tau_{i j}, 1\right)\right]\right\} ;
\end{aligned}
$$

(b) for Hypothesis 2,

$$
\begin{aligned}
& v_{i}^{h}(x, \alpha) \\
& =\min \left\{\min _{u \in \Gamma_{i}(\alpha)}\left\{\left(\rho+\left|q_{\alpha \alpha}\right|+\sum_{j=1}^{2} \frac{\left|u_{j}-d_{j}\right|}{h_{j}}\right)^{-1}\left[\sum_{j=1}^{2} \frac{\left|u_{j}-d_{j}\right|}{h_{j}} v_{i}^{h}\left(x\left(h_{j},+\right) \operatorname{Ind}\left(u_{j}-d_{j} \geq 0\right)+v_{i}^{h}\left(x\left(h_{j},-\right)\right) \operatorname{Ind}\left(u_{j}-d_{j}<0\right)\right)+g(x)+\sum_{\beta \neq \alpha} q_{\alpha \beta} * v_{i}^{h}(x, \beta)\right]\right\} ;\right. \\
& \left.\min _{j \neq i}\left[R_{i j}\left(x, \widehat{\Theta_{i j}}\right)+e^{-\rho \widehat{\Theta_{i j}}} \cdot v_{j}\left(x-d \widehat{\Theta_{i j}}, 1\right)\right]\right\}
\end{aligned}
$$

with

$$
\begin{aligned}
& v_{i}^{h}\left(x\left(h_{j},+\right)\right)=v_{i}^{h}\left(x_{1}, \ldots, x_{j}+h, \ldots, x_{2}\right), \\
& v_{i}^{h}\left(x\left(h_{j},-\right)\right)=v_{i}^{h}\left(x_{1}, \ldots, x_{j}-h, \ldots, x_{2}\right) .
\end{aligned}
$$

$$
\begin{aligned}
P_{h}^{\alpha}\left(x, x \pm h_{j}, u\right) & =\frac{\left|u_{j}-d_{j}\right|}{h_{j} Q_{h}{ }^{\alpha}(x, u)}, \\
\widetilde{P}_{h}{ }^{\alpha}(x, \alpha, \beta, u) & =\frac{q_{\alpha \beta}}{Q_{h}{ }^{\alpha}(x, u)} .
\end{aligned}
$$

For all $\alpha \in M$, let us define the following expressions:

$$
Q_{h}{ }^{\alpha}(x, u)=\left|q_{\alpha \alpha}\right|+\sum_{j=1}^{2} \frac{\left|u_{j}-d_{j}\right|}{h_{j}},
$$

Substituting these expressions in (21) and (22), we obtain the following two equations:

(a) for Hypothesis 1,

$$
\begin{aligned}
& v_{i}^{h}(x, \alpha) \\
& \quad=\min \left\{\min _{u \in \Gamma_{i}(\alpha)}\left\{\frac{Q_{h}^{\alpha}(x, u)}{\rho+Q_{h}^{\alpha}(x, u)}\left\langle\sum_{j=1}^{2} P_{h}^{\alpha}\left(x, x \pm h_{j}, u\right) v_{i}^{h}(x, \alpha)+\sum_{\beta \neq \alpha} \widetilde{P}_{h}^{\alpha}(x, \alpha, \beta, u) \cdot v_{i}^{h}(x, \beta)\right\rangle+\frac{g(x)}{\rho+Q_{h}{ }^{\alpha}(x, u)}\right\}\right. \\
& \left.\quad \cdot \min _{j \neq i}\left[R_{i j}\left(x, \Theta_{i j}\right)+\left(P_{i j}\right) e^{-\rho \Theta_{i j}} \cdot v_{j}\left(x-d \Theta_{i j}, 1\right)+\left(1-P_{i j}\right) e^{-\rho \Theta_{i j}} \cdot v_{j}\left(x-d \tau_{i j}, 1\right)\right]\right\}
\end{aligned}
$$


(b) for Hypothesis 2,

$$
\begin{aligned}
& v_{i}^{h}(x, \alpha) \\
& \quad=\min \left\{\min _{u \in \Gamma_{i}(\alpha)}\left\{\frac{Q_{h}{ }^{\alpha}(x, u)}{\rho+Q_{h}{ }^{\alpha}(x, u)}\left\langle\sum_{j=1}^{2} P_{h}{ }^{\alpha}\left(x, x \pm h_{j}, u\right) v_{i}{ }^{h}(x, \alpha)+\sum_{\beta \neq \alpha} \widetilde{P}_{h}{ }^{\alpha}(x, \alpha, \beta, u) \cdot v_{i}^{h}(x, \beta)\right\rangle+\frac{g(x)}{\rho+Q_{h}{ }^{\alpha}(x, u)}\right\}\right. \\
& \left.\quad \cdot \min _{j \neq i}\left[R_{i j}\left(x, \widehat{\Theta_{i j}}\right)+e^{-\rho \widehat{\Theta_{i j}}} \cdot v_{j}\left(x-d \widehat{\Theta_{i j}}, 1\right)\right]\right\} .
\end{aligned}
$$

Let us specify the terms of the previous equations, the discretization domain, and the limit conditions and illustrate the algorithm used to solve the modified numerical version of the HJB equations obtained. In addition, (25) and (26) correspond to four equations, expressing the optimality conditions concerning the production system under study, involving two products and a machine with two modes.

(i) Hypothesis 1. Let us denote by $P_{12}$ the probability that the machine is in failure mode at the end of a setup from $P_{1}$ to $P_{2}$, if it was operational when the setup started, and by $\tau_{12}$ the corresponding failure time. Similarly, $P_{21}$ is the probability that the machine is in failure mode at the end of a setup from $P_{2}$ to $P_{1}$, if it was operational when the setup started, with $\tau_{21}$ denoting the corresponding failure time. According to the random machine failure process,

$$
P_{12}=e^{-q_{12} \Theta_{12}} .
$$

In order to calculate $\tau_{12}$ we evaluate the conditional expectation $E\left\{t \mid t<\Theta_{12}\right\}$ and obtain

$$
\tau_{12}=\frac{1}{q_{12}}\left(1-e^{-q_{12} \Theta_{12}}\left(1+q_{12} \Theta_{12}\right)\right) .
$$

For the setup from product 2 to product 1 , we have $P_{12}=$ $e^{-q_{12} \Theta_{21}}$ and

$$
\tau_{21}=\frac{1}{q_{12}}\left(1-e^{-q_{12} \Theta_{21}}\left(1+q_{12} \Theta_{21}\right)\right) .
$$

We then have

$$
\begin{aligned}
& v_{1}{ }^{h}(x, 1)=\min \left\{\min _{u_{1} \in \Gamma_{1}(1)}\left\{\frac{Q_{h}{ }^{1}(x, u)}{\rho+Q_{h}{ }^{1}(x, u)}\left\langle\sum_{j=1}^{2} P_{h}{ }^{1}\left(x, x \pm h_{j}, u\right) v_{1}{ }^{h}(x, 1)+\widetilde{P}_{h}{ }^{1}(x, 1,2, u) \cdot v_{1}{ }^{h}(x, 2)\right\rangle+\frac{g(x)}{\rho+Q_{h}{ }^{1}(x, u)}\right\}\right. \\
& \left.\cdot\left[R_{12}\left(x, \Theta_{12}\right)+\left(P_{12}\right) e^{-\rho \Theta_{12}} \cdot v_{2}{ }^{h}\left(x_{1}-d_{1} \Theta_{12}, 1, x_{2}-d_{2} \Theta_{12}, 1\right)+\left(1-P_{12}\right)\left[e^{-\rho \tau_{12}} \cdot v_{1}^{h}\left(x_{1}-d_{1} \tau_{12}, 1, x_{2}-d_{2} \tau_{12}, 1\right)\right]\right]\right\} \text {, } \\
& v_{2}{ }^{h}(x, 1)=\min \left\{\min _{u_{2} \in \Gamma_{2}(1)}\left\{\frac{Q_{h}{ }^{1}(x, u)}{\rho+Q_{h}{ }^{1}(x, u)}\left\langle\sum_{j=1}^{2} P_{h}{ }^{1}\left(x, x \pm h_{j}, u\right) v_{2}{ }^{h}(x, 1)+\widetilde{P}_{h}{ }^{1}(x, 1,2, u) \cdot v_{2}{ }^{h}(x, 2)\right\rangle+\frac{g(x)}{\rho+Q_{h}{ }^{1}(x, u)}\right\}\right. \\
& \left.\cdot\left[R_{21}\left(x, \Theta_{21}\right)+\left(P_{12}\right) e^{-\rho \Theta_{21}} \cdot v_{1}{ }^{h}\left(x_{1}-d_{1} \Theta_{21}, 1, x_{2}-d_{2} \Theta_{21}, 1\right)+\left(1-P_{12}\right)\left[e^{-\rho \tau_{21}} \cdot v_{2}{ }^{h}\left(x_{1}-d_{1} \tau_{21}, 1, x_{2}-d_{2} \tau_{21}, 1\right)\right]\right]\right\} \text {, } \\
& v_{1}{ }^{h}(x, 2)=\min \left\{\frac{Q_{h}{ }^{2}(x, 0)}{\rho+Q_{h}{ }^{2}(x, 0)}\left\langle\sum_{j=1}^{2} P_{h}{ }^{2}\left(x, x \pm h_{j}, 0\right) v_{1}{ }^{h}(x, 2)+\widetilde{P}_{h}{ }^{1}(x, 2,1,0) \cdot v_{1}{ }^{h}(x, 1)\right\rangle+\frac{g(x)}{\rho+Q_{h}{ }^{2}(x, 0)}\right\}, \\
& v_{2}{ }^{h}(x, 2)=\min \left\{\frac{Q_{h}{ }^{2}(x, 0)}{\rho+Q_{h}{ }^{2}(x, 0)}\left\langle\sum_{j=1}^{2} P_{h}{ }^{2}\left(x, x \pm h_{j}, 0\right) v_{2}{ }^{h}(x, 2)+\widetilde{P}_{h}{ }^{1}(x, 2,1,0) \cdot v_{2}{ }^{h}(x, 1)\right\rangle+\frac{g(x)}{\rho+Q_{h}{ }^{2}(x, 0)}\right\} \text {. }
\end{aligned}
$$


We notice that the setup expression no longer appears in both failure mode equations and that the first two operational mode equations are different from the equivalent equations for the reference hypothesis of the literature. (ii) Hypothesis 2. Using a known formula $=\Theta_{12} / \mathrm{MTTF}$, we get the terms of the corrections due to repairs $r_{12}=$ $\left(\Theta_{12} *\right.$ MTTR $) /$ MTTF and $r_{21}=\left(\Theta_{21} *\right.$ MTTR $) /$ MTTF (here $\left.\mathrm{MTTF}=1 / q_{12}\right)$. Finally, the modified setup time is calculated:

$$
\begin{aligned}
& \widehat{\Theta_{12}}=\Theta_{12}+\frac{\Theta_{12} * \text { MTTR }}{\text { MTTF }}, \\
& \widehat{\Theta_{21}}=\Theta_{21}+\frac{\Theta_{21} * \text { MTTR }}{\text { MTTF }}, \\
& v_{1}^{h}(x, 1) \\
& =\min \left\{\min _{u_{1} \in \Gamma_{1}(1)}\left\{\frac{Q_{h}{ }^{1}(x, u)}{\rho+Q_{h}{ }^{1}(x, u)}\left\langle\sum_{j=1}^{2} P_{h}{ }^{1}\left(x, x \pm h_{j}, u\right) v_{1}{ }^{h}(x, 1)+\widetilde{P}_{h}{ }^{1}(x, 1,2, u) \cdot v_{1}{ }^{h}(x, 2)\right\rangle+\frac{g(x)}{\rho+Q_{h}{ }^{1}(x, u)}\right\}\right. \\
& \left.\cdot\left[R_{12}\left(x, \widehat{\Theta_{12}}\right)+e^{-\rho \widehat{\Theta_{12}}} \cdot v_{2}^{h}\left(x_{1}-d_{1} \widehat{\Theta_{12}}, 1, x_{2}-d_{2} \widehat{\Theta_{12}}, 1\right)\right]\right\}, \\
& v_{2}^{h}(x, 1) \\
& =\min \left\{\min _{u_{1} \in \Gamma_{1}(1)}\left\{\frac{Q_{h}{ }^{1}(x, u)}{\rho+Q_{h}{ }^{1}(x, u)}\left\langle\sum_{j=1}^{2} P_{h}{ }^{1}\left(x, x \pm h_{j}, u\right) v_{2}{ }^{h}(x, 1)+\widetilde{P}_{h}{ }^{1}(x, 1,2, u) \cdot v_{2}{ }^{h}(x, 2)\right\rangle+\frac{g(x)}{\rho+Q_{h}{ }^{1}(x, u)}\right\}\right. \\
& \left.\cdot\left[R_{21}\left(x, \widehat{\Theta_{21}}\right)+e^{-\rho \widehat{\Theta_{21}}} \cdot v_{1}^{h}\left(x_{1}-d_{1} \widehat{\Theta_{21}}, 1, x_{2}-d_{2} \widehat{\Theta_{21}}, 1\right)\right]\right\} \text {, } \\
& v_{1}{ }^{h}(x, 2)=\min \left\{\frac{Q_{h}{ }^{2}(x, 0)}{\rho+Q_{h}{ }^{2}(x, 0)}\left\langle\sum_{j=1}^{2} P_{h}{ }^{2}\left(x, x \pm h_{j}, 0\right) v_{1}{ }^{h}(x, 2)+\widetilde{P}_{h}{ }^{1}(x, 2,1,0) \cdot v_{1}{ }^{h}(x, 1)\right\rangle+\frac{g(x)}{\rho+Q_{h}{ }^{2}(x, 0)}\right\}, \\
& v_{2}{ }^{h}(x, 2)=\min \left\{\frac{Q_{h}{ }^{2}(x, 0)}{\rho+Q_{h}{ }^{2}(x, 0)}\left\langle\sum_{j=1}^{2} P_{h}{ }^{2}\left(x, x \pm h_{j}, 0\right) v_{2}{ }^{h}(x, 2)+\widetilde{P}_{h}{ }^{1}(x, 2,1,0) \cdot v_{2}{ }^{h}(x, 1)\right\rangle+\frac{g(x)}{\rho+Q_{h}{ }^{2}(x, 0)}\right\} .
\end{aligned}
$$

We also notice that the setup expression no longer appears in both of the failure mode equations and that the first two operational mode equations are similar to those of the reference hypothesis (with the setup times modified), but different from equations related to the case of Hypothesis 1. In the next section, we present a numerical example and analyze the results obtained in different situations.

\section{Numerical Example and Results Analysis}

In order to characterize the production and setup policies and to show the influence of the interactions between the setup procedure and the random machine failure process, for two new hypotheses in comparison with the reference hypothesis, we present three different cases in three data groups. The first two groups had identical economic parameters, and only technical parameters such as the setup duration were varied according to the groups. In the third group, both products had different economic parameters. Table 1 shows the constant parameters for the numerical examples considered, with

$$
\begin{aligned}
c_{1}^{-} & =c_{2}^{-} ; \\
c_{1}^{+} & =c_{2}^{+} ; \\
K_{12} & =K_{21} ; \\
d_{1} & =d_{2} ; \\
U_{1}^{+} & =U_{2}^{+}
\end{aligned}
$$

for the two first groups.

In addition,

(i) group 1 represents the case $\Theta_{12}=\Theta_{21}=1.25$;

(ii) group 2 represents the case $\Theta_{12}=\Theta_{21}=1.75$;

(iii) group 3 is the case of two nonidentical products $\Theta_{12}=$ $\Theta_{21}=1.25$ and $C_{1}^{+}=C_{2}^{+}=1 ; C_{1}^{-}=20 ; C_{2}^{-}=40$. 
TABLE 1: Data parameters.

\begin{tabular}{ccccccccccc}
\hline$c_{1}^{-}$ & $c_{1}^{+}$ & $K_{12}$ & $U_{1}^{+}$ & $d_{1}$ & $x_{1}^{+}$ & $x_{1}^{-}$ & $q_{12}$ & $q_{21}$ & $\rho$ & $h_{x_{1}^{+}}$ \\
\hline 20 & 1 & 0.5 & 5 & 1.5 & 20 & -5 & 0.1 & 0.8 & 0.1 & 0.2 \\
\hline
\end{tabular}

TABLE 2: Setup times for machine tools (Boothroyd et al. [15]).

\begin{tabular}{|c|c|c|c|}
\hline \multicolumn{4}{|c|}{ Some nonproductive times for common machine tools } \\
\hline Machine tool & Time to engage tool and so forth (s) & Basic setup time (h) & Additional setup per tool (h) \\
\hline Horizontal band saw & - & 0.17 & - \\
\hline Manual turret lathe & 9 & 0.15 & 0.2 \\
\hline NC turret lathe & 1.5 & 0.5 & 0.15 \\
\hline Milling machine & 30 & 1.5 & - \\
\hline Drilling machine & 9 & 1 & - \\
\hline Horizontal-boring machine & 30 & 1.3 & - \\
\hline Broaching machine & 13 & 0.6 & - \\
\hline Gear hobbling machine & 39 & 0.9 & - \\
\hline Grinding machine & 19 & 0.6 & - \\
\hline Internal grinding machine & 24 & 0.6 & - \\
\hline Machining center & 8 & 0.7 & 0.05 \\
\hline
\end{tabular}

The setup times are given by the table of the machine tools setup times (see Table 2).

With these data, the system is capable of producing with setup at the request of both products if the following feasibility condition is satisfied:

$$
U_{\max }^{i} \frac{q_{21}}{q_{12}+q_{21}} e^{-q_{12} \theta_{12}}>d_{1}, d_{2} \quad(i=1,2) .
$$

We present six figures for every case (three figures for each product). Each figure contains the production or setup policies for the two new hypotheses and for the reference hypothesis. For group 1, Figures 3 and 6, respectively, illustrate the production policy of $P_{1}$ and $P_{2}$ for three hypotheses. Then, also for group 1, Figures 4 and 7 illustrate the setup policies for $P_{1}$ to $P_{2}$ and for $P_{2}$ to $P_{1}$, respectively. Finally, for group 1, Figures 5 and 8, respectively, illustrate the association of both policies (production and setup) for $P_{1}$ and the association of both policies (production and setup) for $P_{2}$. In the next section, analyses of sensibility will be provided to study the effects of variation of the various costs on the control policies.

Group 1 (product type 1) $\Theta_{12}=\Theta_{21}=1.25$ (see Figures 3-5).

Group 1 (product type 2) $\Theta_{12}=\Theta_{21}=1.25$ (see Figures 6-8).

Group 2 (product type 1) $\Theta_{12}=\Theta_{21}=1.75$ (see Figures 9-11).

Group 2 (product type 2) $\Theta_{12}=\Theta_{21}=1.75$ (see Figures 12-14).

Group 3 (product type 1) $\Theta_{12}=\Theta_{21}=1.25$ and $C_{1}^{+}=$ $1 ; C_{1}^{-}=20$ (see Figures 15-17).

Group 3 (product type 2) $\Theta_{12}=\Theta_{21}=1.25$ and $C_{1}^{+}=$ $1 ; C_{1}^{-}=20$ (see Figures 18-20).

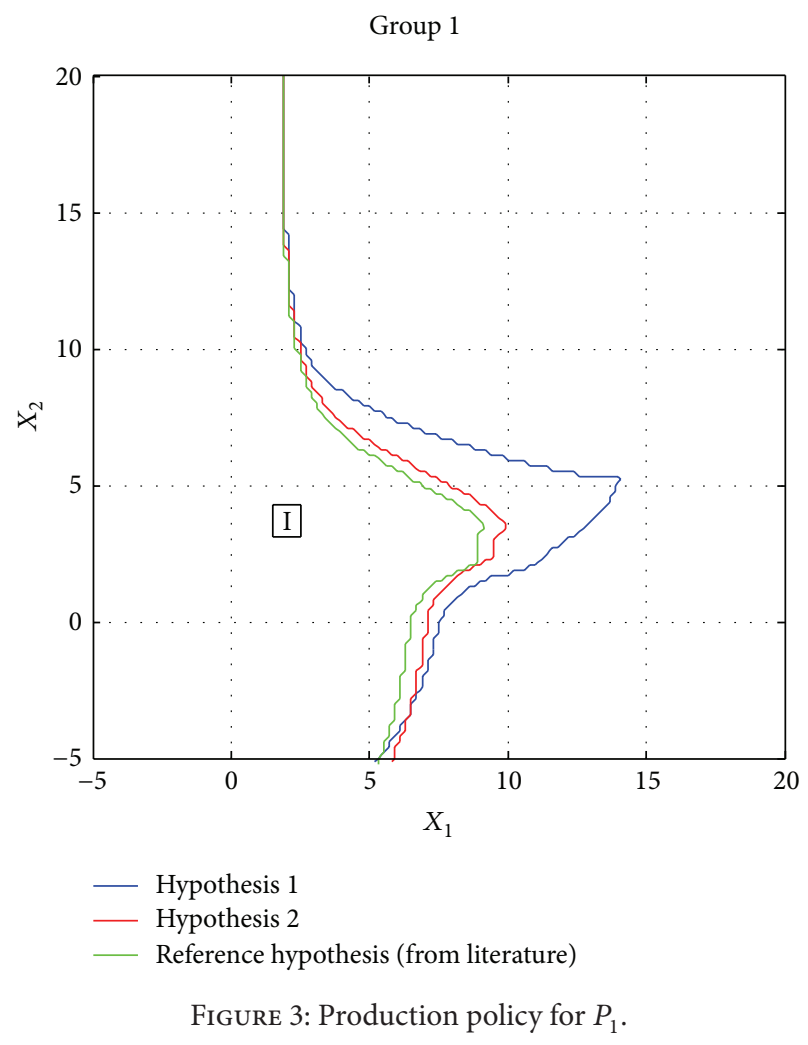

Let us now interpret the results obtained and illustrated by Figures 3-20. This analysis will allow us to present the structure of the production and setup policies for the two product part types and with regard to the formulated hypotheses. 
Group 1

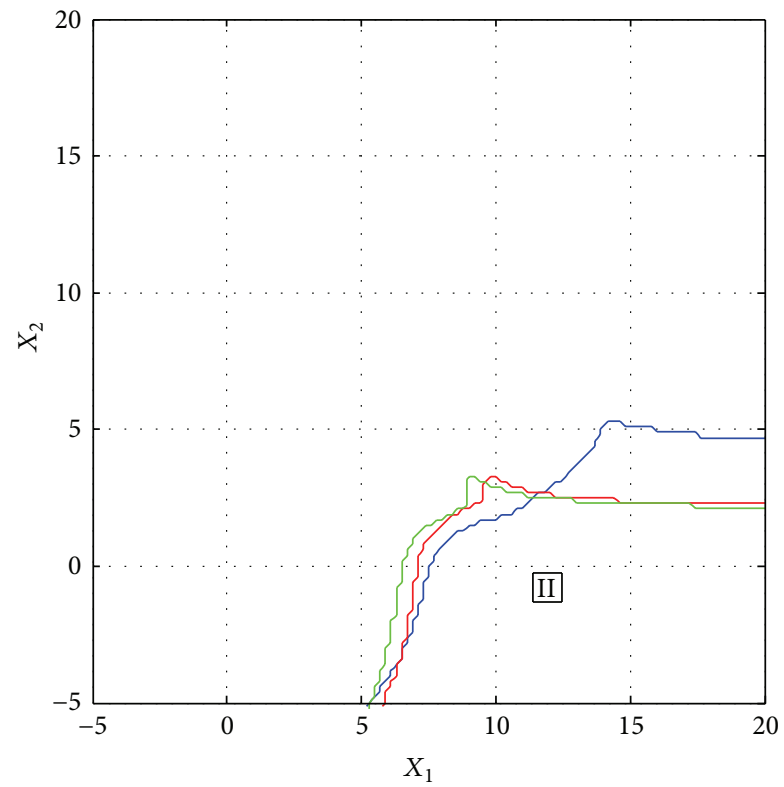

Hypothesis 1

Hypothesis 2

- Reference hypothesis (from literature)

FIGURE 4: Setup policy (product 1 to product 2).

Group 1

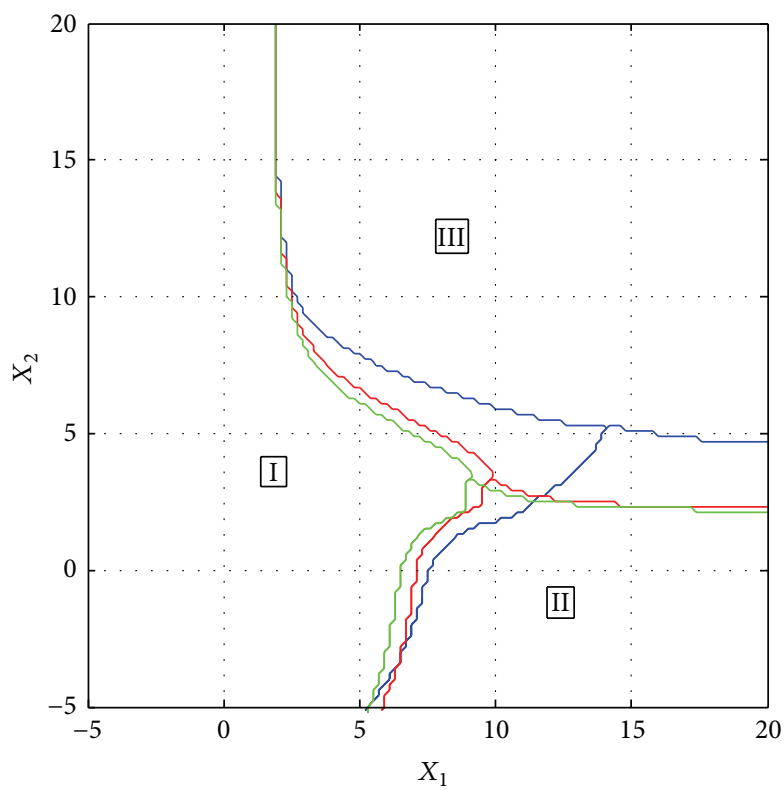

- Hypothesis 1

- Hypothesis 2

_ Reference hypothesis (from literature)

FIgURE 5: Production policy for $P_{1}$ and setup policy $\left(P_{1}\right.$ to $\left.P_{2}\right)$.
Group 1

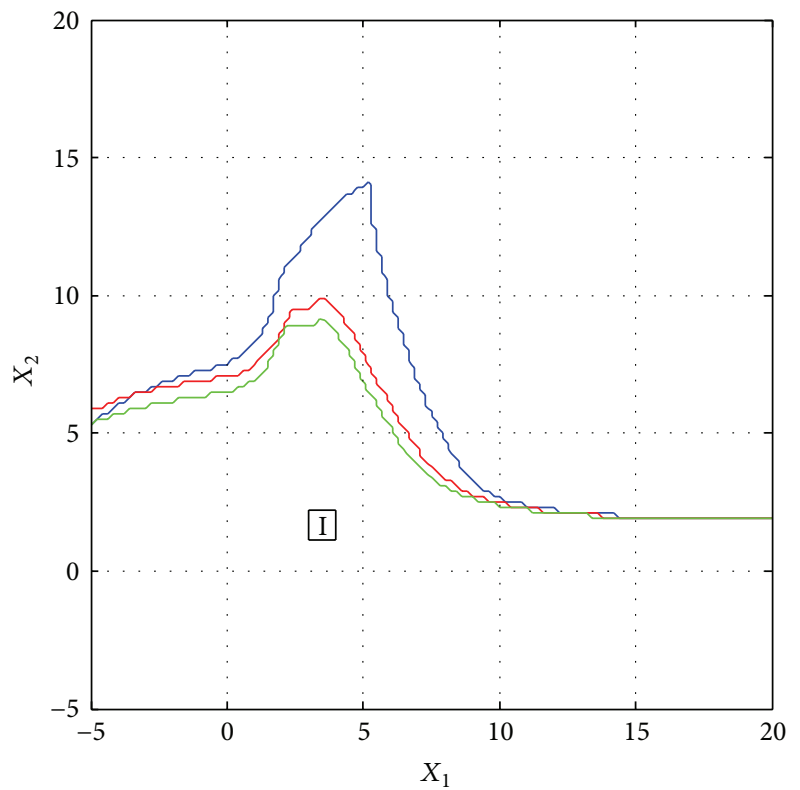

Hypothesis 1

Hypothesis 2

_ Reference hypothesis (from literature)

Figure 6: Production policy for $P_{2}$.

Group 1

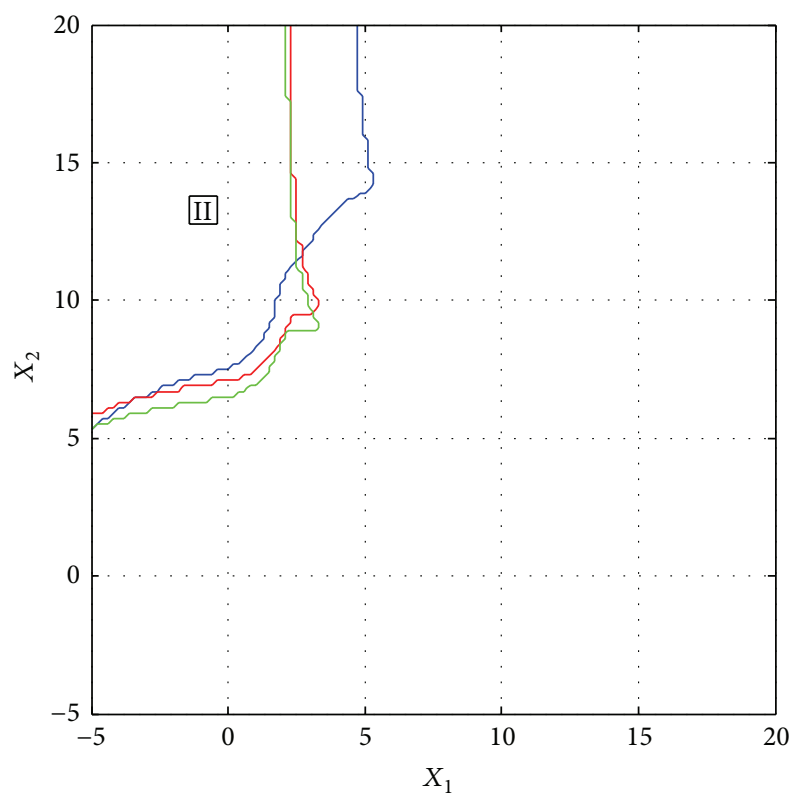

- Hypothesis 1

- Hypothesis 2

— Reference hypothesis (from literature)

FIGURE 7: Setup policy (product 2 to product 1 ). 

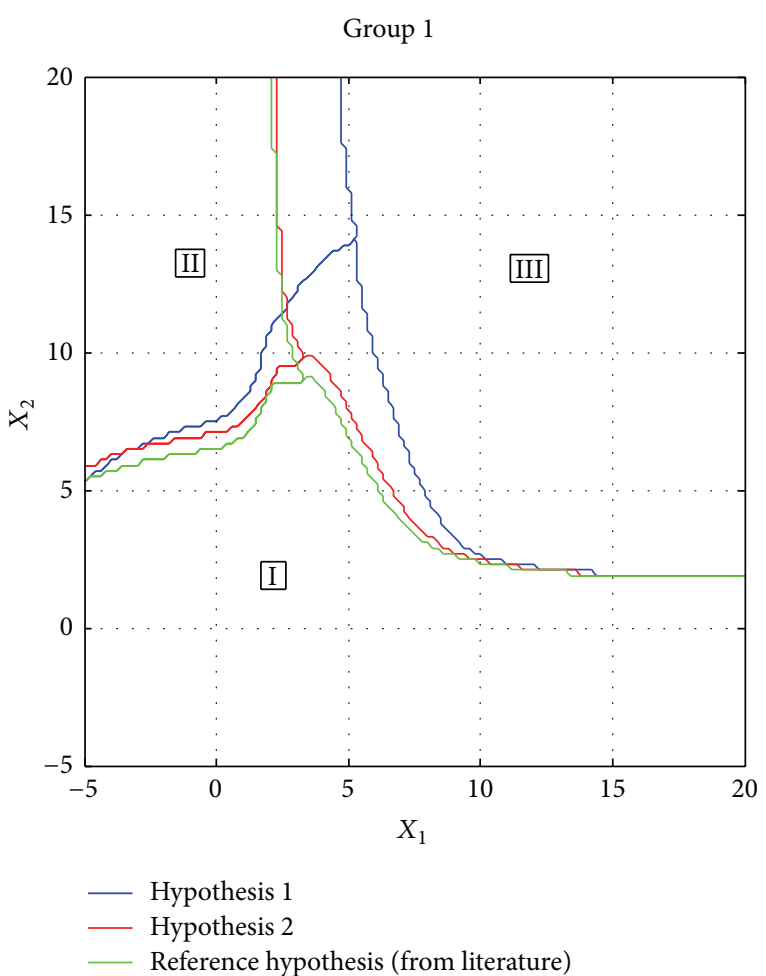

Figure 8: Production policy for $P_{2}$ and setup policy $\left(P_{2}\right.$ to $\left.P_{1}\right)$.
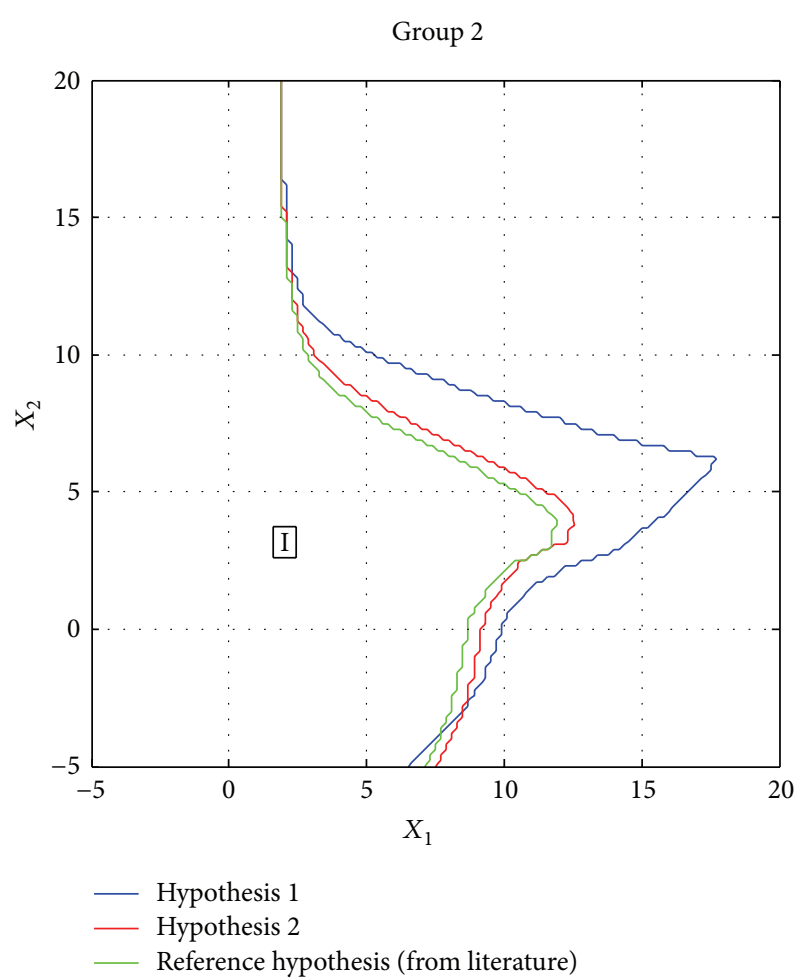

Figure 9: Production policy for $P_{1}$.

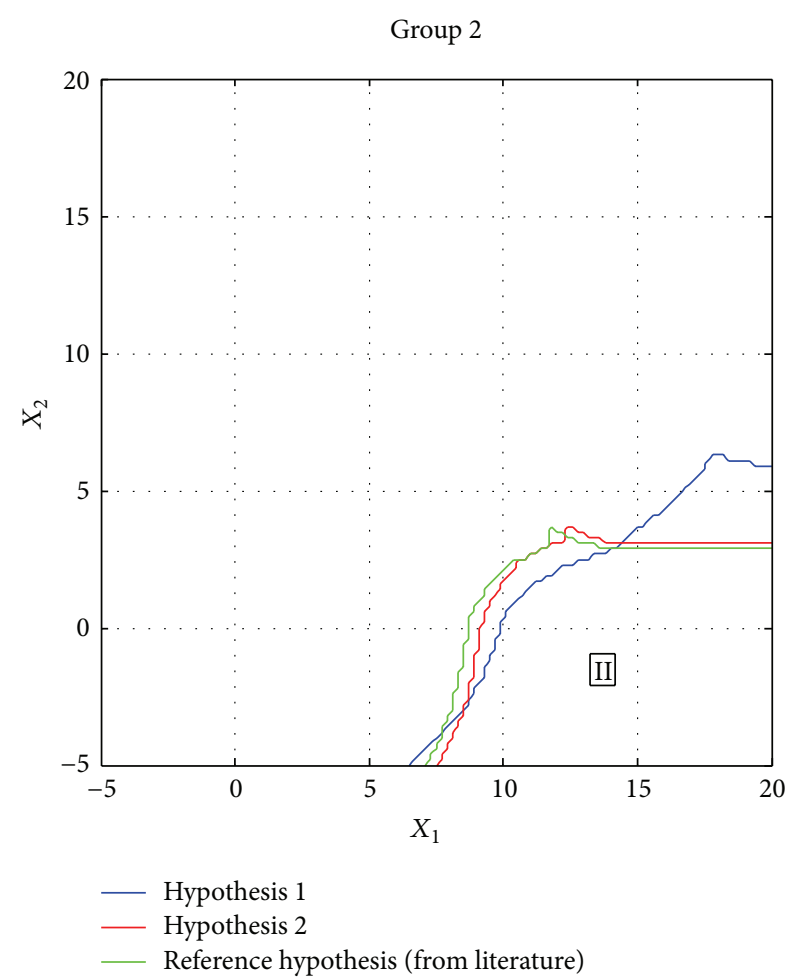

Figure 10: Setup policy (product 1 to product 2).

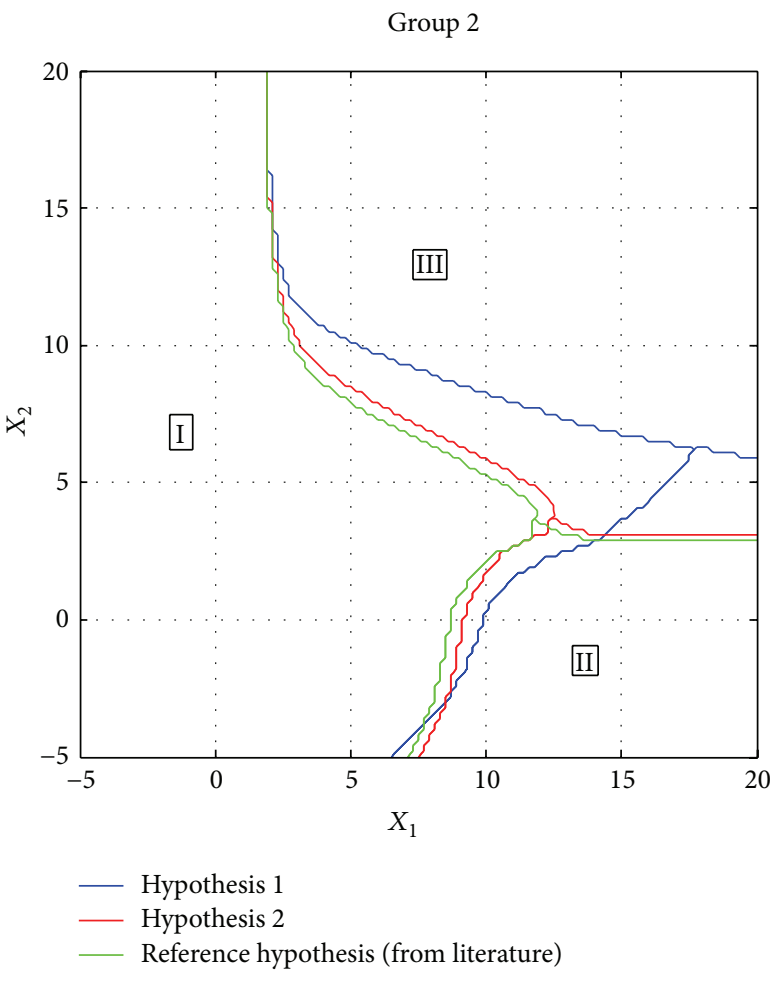

FIgUre 11: Production policy for $P_{1}$ and setup policy (product 1 to product 2). 


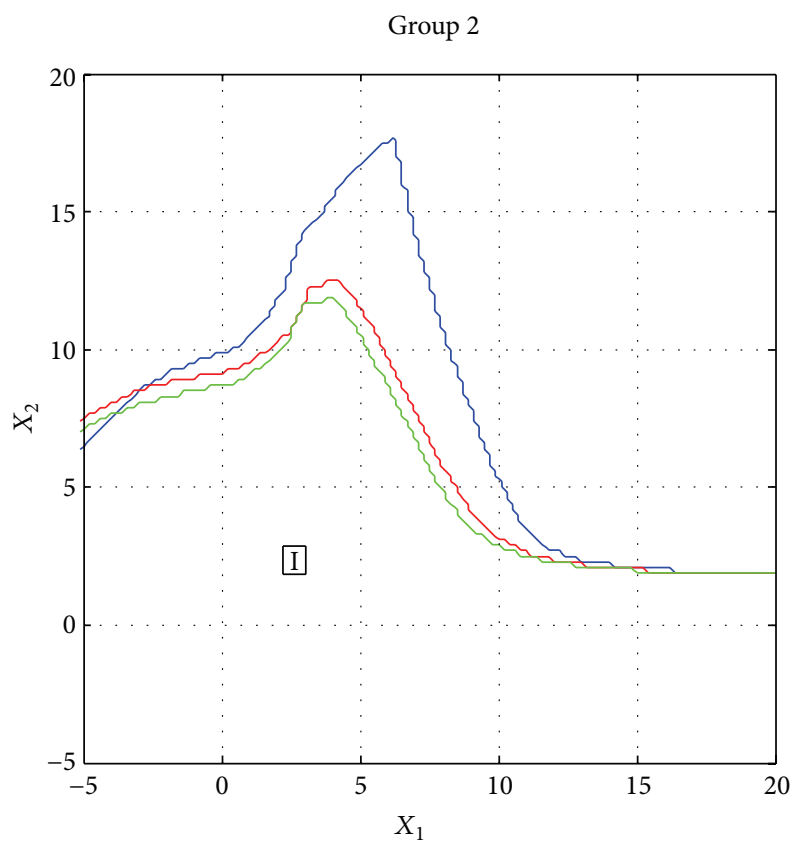

- Hypothesis 1

- Hypothesis 2

— Reference hypothesis (from literature)

Figure 12: Production policy for $P_{2}$.

Group 2

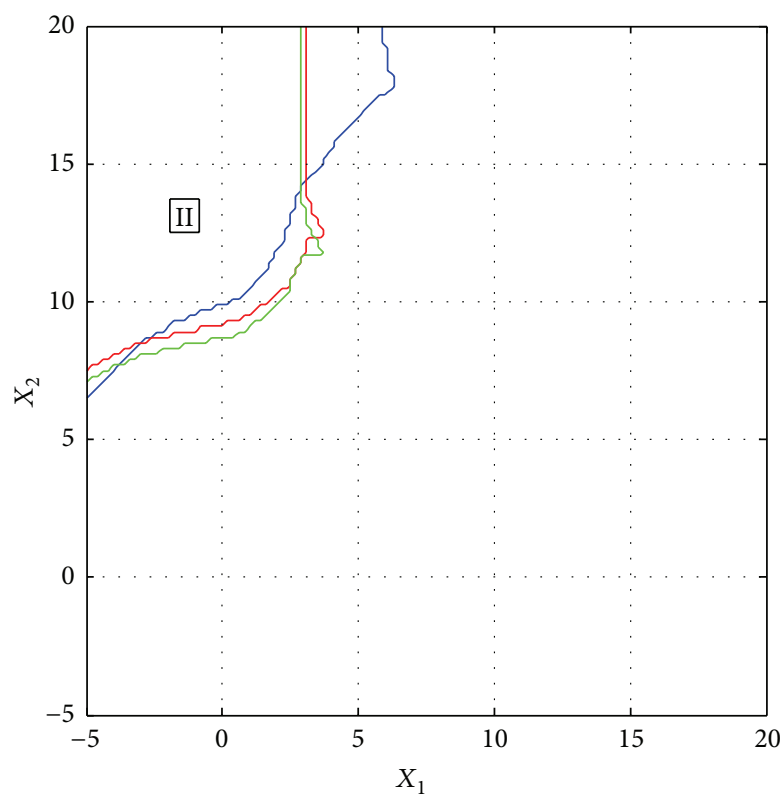

- Hypothesis 1

- Hypothesis 2

— Reference hypothesis (from literature)

FIGURE 13: Setup policy (product 2 to product 1).

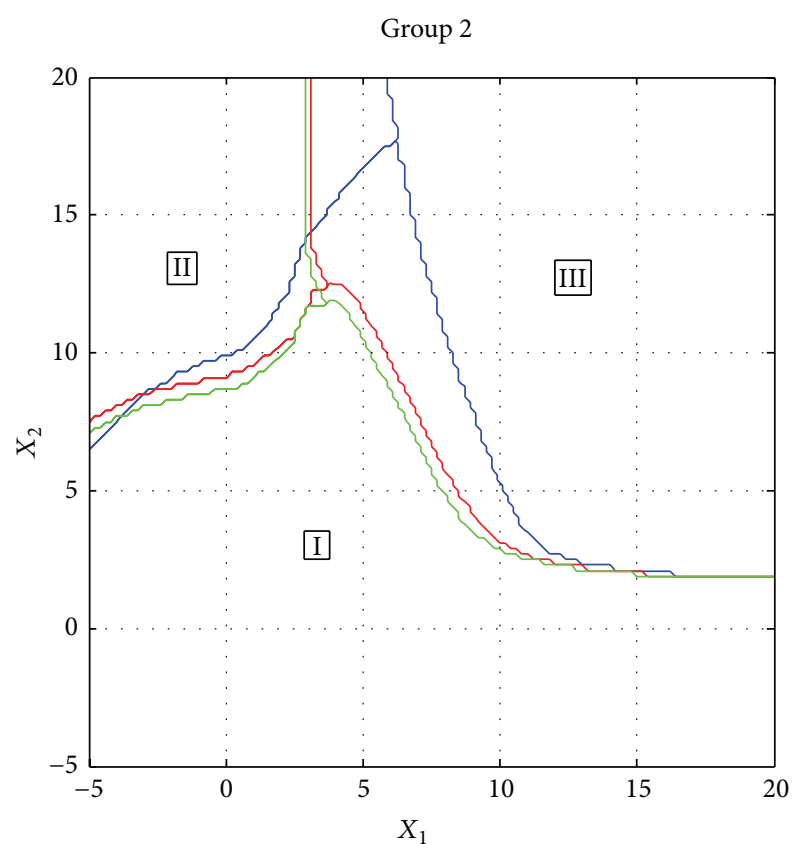

Hypothesis 1

Hypothesis 2

Reference hypothesis (from literature)

FIGURE 14: Production policy for $P_{2}$ and setup policy (product 2 to product 1).

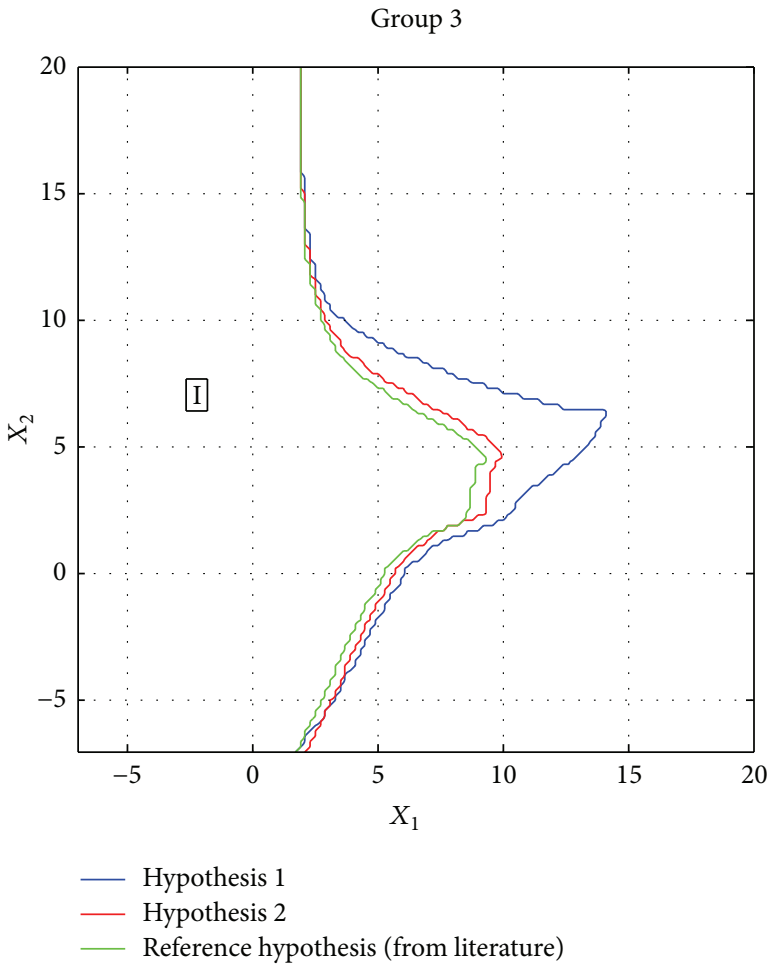

Figure 15: Production policy for $P_{1}$. 


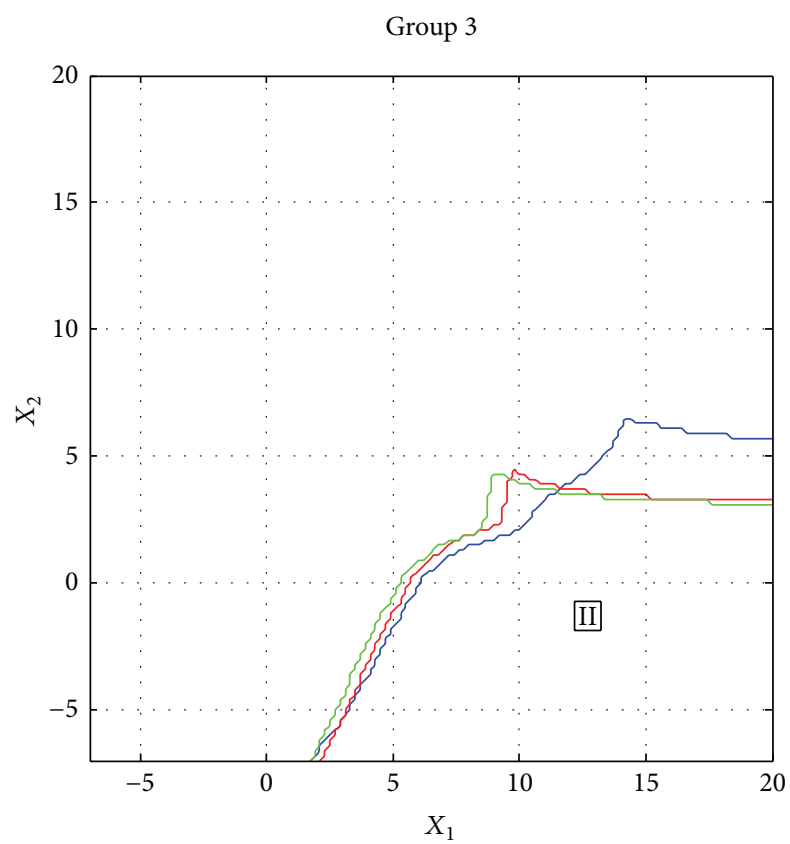

- Hypothesis 1
— Hypothesis 2
Reference hypothesis (from literature)

FIGURE 16: Setup policy (product 1 to product 2).
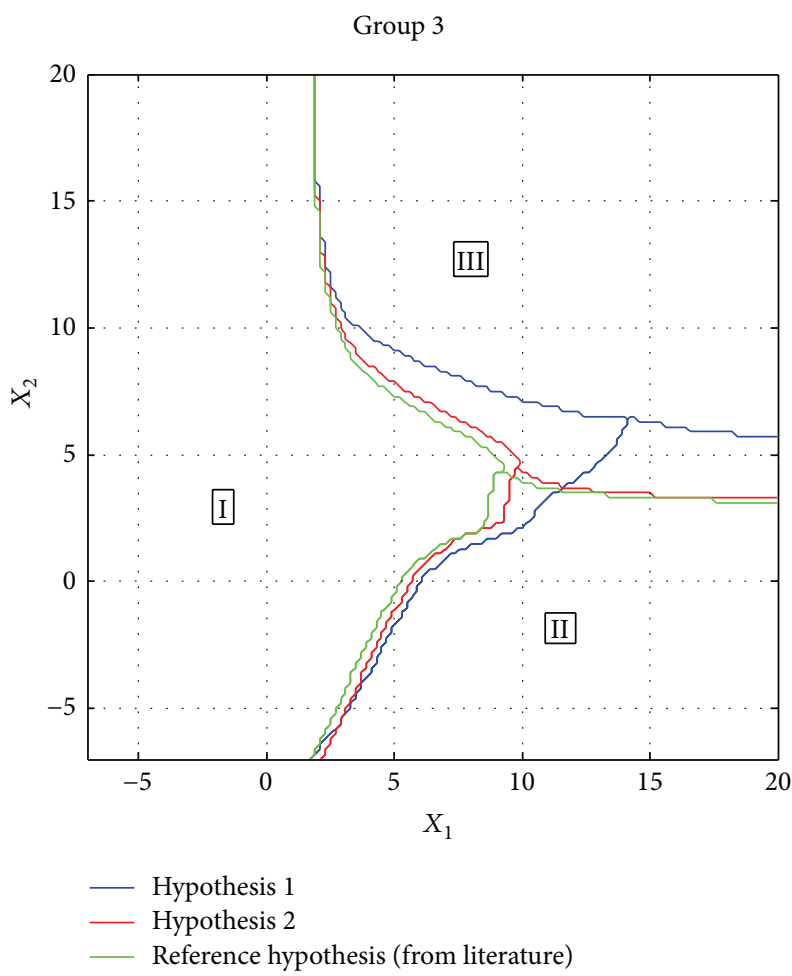

FIgURE 17: Production policy for $P_{1}$ and setup policy (product 1 to product 2).

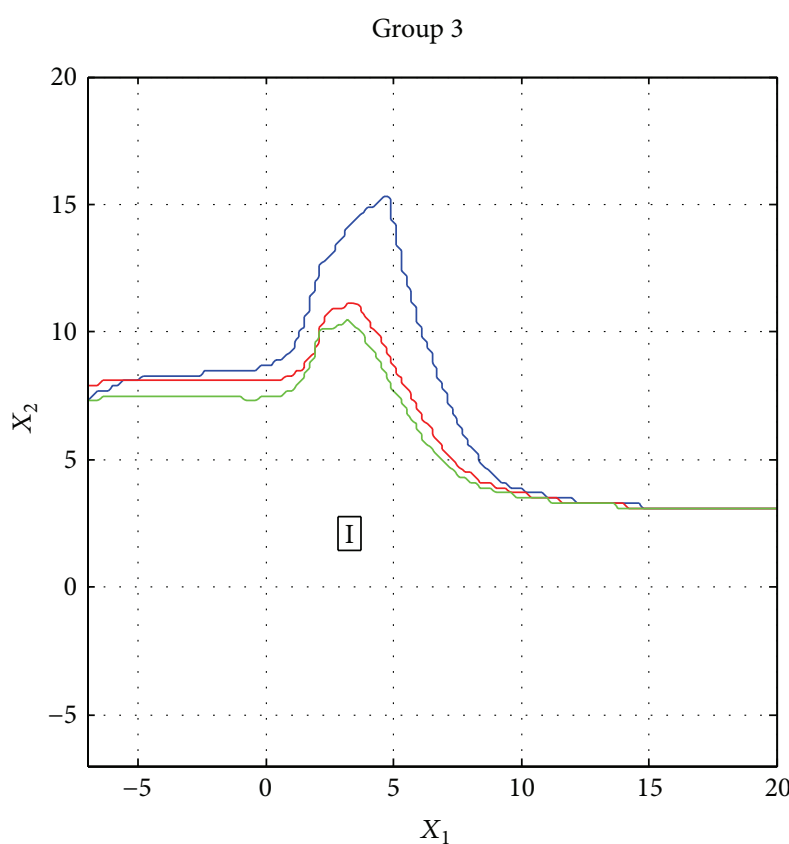

Hypothesis 1

Hypothesis 2

_ Reference hypothesis (from literature)

FIGURE 18: Production policy for $P_{2}$.

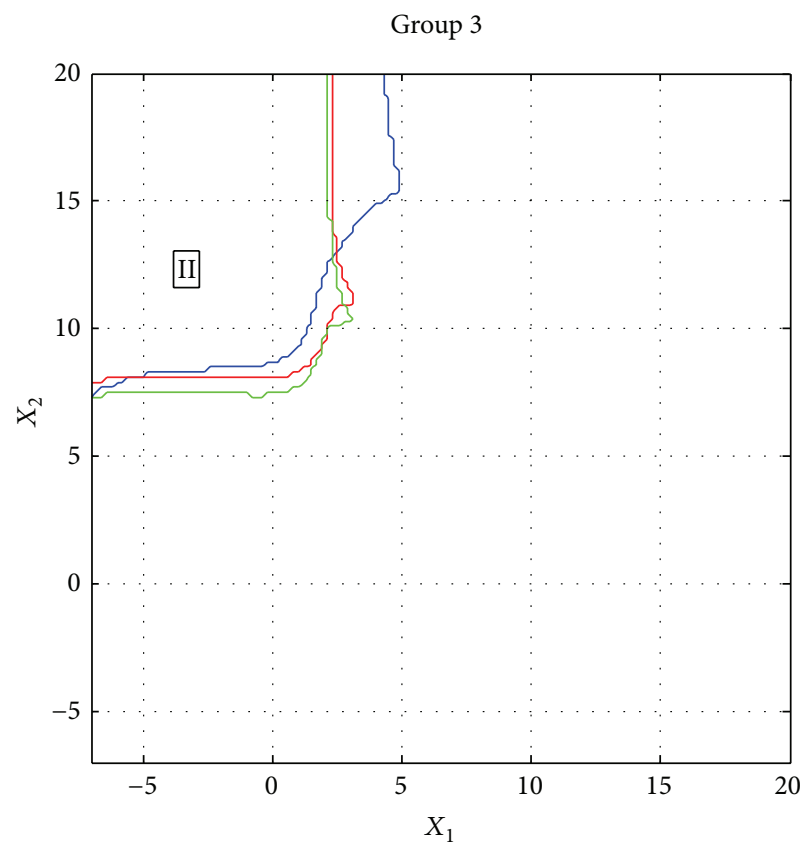

- Hypothesis 1

- Hypothesis 2

— Reference hypothesis (from literature)

FIGURE 19: Setup policy (product 2 to product 1). 
Group 3

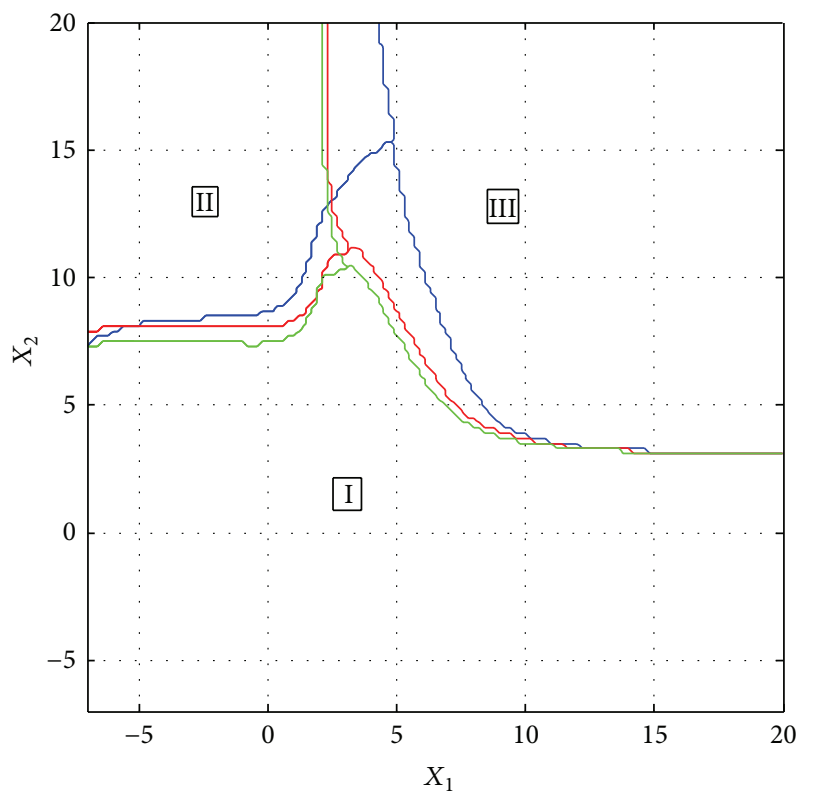

- Hypothesis 1
- Hypothesis 2
Reference hypothesis (from literature)

Figure 20: Production policy for $P_{2}$ and setup policy (product 2 to product 1).

5.1. Optimal Production Policy. An analysis of three cases shows that we have to produce at the maximum rate in region I when the machine is configured for the same product. In region II, the machine is configured (according to the setup policy) for the production of the other type of product. In region III, the production policy recommends stopping the machine and producing nothing by setting the production rate to zero. It is interesting to note that, in Hypothesis 1 , the optimal inventory level is very big, contrary to Hypothesis 2 and to the reference hypothesis, as seen in Bai and Elhafsi [14], Boukas and Kenné [10], and Hajji et al. [11]. This increase in the inventory level is understandable given that if a breakdown occurs during the setup operation, we have to stop the setup until the machine repair is completed. This breakdown cancels all the data relative to the setup activities started before the failure. In this case, the operator has to resume the setup operation, which increases the overall setup time and leads to a loss of availability of the machine. According to Hypothesis 2, the optimal inventory level is slightly bigger than that of the reference hypothesis. This light increase in the inventory level is understandable, given that the setup operation must be stopped when a breakdown occurs. This breakdown does not cancel all the data relative to the setup activities (contrary to Hypothesis 1). The operator pursues the setup activities after the repair of the machine. The global setup time of Hypothesis 2 is then higher than that of the reference hypothesis. In fact, we have a loss of availability of the machine, but to a smaller extent than in the case of Hypothesis 1. The optimal production policy is
TABLE 3: Comparative study of optimal threshold inventory levels.

\begin{tabular}{lccc}
\hline Group & Hypothesis 1 & Hypothesis 2 & Literature hypothesis \\
\hline \multirow{2}{*}{1} & $Z_{1}=14$ & $Z_{1}=9.8$ & $Z_{1}=9$ \\
& $Z_{2}=14$ & $Z_{2}=9.8$ & $Z_{2}=9$ \\
\hline \multirow{2}{*}{2} & $Z_{1}=17.6$ & $Z_{1}=12.4$ & $Z_{1}=11.8$ \\
& $Z_{2}=17.6$ & $Z_{2}=12.4$ & $Z_{2}=11.8$ \\
\hline \multirow{3}{*}{3} & $Z_{1}=14$ & $Z_{1}=9.8$ & $Z_{1}=9$ \\
& $Z_{2}=15.2$ & $Z_{2}=11$ & $Z_{2}=10.4$ \\
\hline
\end{tabular}

then of hedging policy structure and can be expressed by the following two equations (for product 1 and product 2):

$$
\begin{aligned}
& u_{1}\left(x_{1}, x_{2}\right)= \begin{cases}U_{1}^{+} & \text {if } x_{1}<Z_{1}\left(x_{2}\right) \\
0 & \text { if } x_{1}>Z_{1}\left(x_{2}\right),\end{cases} \\
& u_{2}\left(x_{1}, x_{2}\right)= \begin{cases}U_{2}^{+} & \text {if } x_{2}<Z_{1}\left(x_{1}\right) \\
0 & \text { if } x_{2}>Z_{1}\left(x_{1}\right) .\end{cases}
\end{aligned}
$$

5.2. Optimal Setup Policy. By analyzing Figures 4 and 5 in region II (zone in which a setup from $P_{1}$ to $P_{2}$ or from $P_{2}$ to $P_{1}$ is allowed), we can observe that the setup policies of Hypotheses 1 and 2 give a margin bigger than that of the reference hypothesis. This trend reduces region III and so allows the system the possibility of performing the setup without any shortage risk for the other product. The setup policies are given in this case by the following expressions:

$$
\begin{aligned}
& S_{12}=\left\{\begin{array}{l}
1 \quad \text { if }\left\{\begin{array} { l } 
{ x _ { 1 } \geq a _ { 1 } , } \\
{ x _ { 2 } \leq 0 }
\end{array} \quad \text { or } \left\{\begin{array}{l}
x_{1}<0 \\
x_{2} \leq-b_{1}
\end{array}\right.\right. \\
0 \quad \text { otherwise }
\end{array}\right. \\
& S_{21}=\left\{\begin{array} { l } 
{ 1 \quad \text { if } \{ \begin{array} { l } 
{ x _ { 1 } \leq c _ { 2 } x _ { 2 } + b _ { 2 } , } \\
{ x _ { 1 } \geq 0 , x _ { 2 } \geq 0 }
\end{array} } \\
{ 0 \quad \text { otherwise } }
\end{array} \text { or } \left\{\begin{array}{l}
x_{2} \geq a_{2}, \\
x_{1} \leq 0
\end{array}\right.\right.
\end{aligned}
$$

with

$$
\begin{aligned}
& 0 \leq a_{1} \leq Z_{1}, \\
& b_{1} \leq 0, \\
& 0 \leq a_{2} \leq Z_{2}, \\
& 0 \leq c_{2} a_{2}+b_{2} \leq Z_{1} .
\end{aligned}
$$

To conclude this section, we recapitulate the results obtained according to the critical thresholds $Z_{1}$ and $Z_{2}$, which characterize the production and setup policies presented by (34) and (35). The values of the optimal threshold inventory levels obtained numerically for the three groups of data are presented in Table 3.

These results show our contribution, given that all the previous works in the literature did not handle the case of industrial systems subjected to Hypotheses 1 and 2. In this paper, we determined the production structures and setup policies for these industrial systems. 


\section{Conclusion}

This research clearly defines the production planning problem and the setup strategies for industrial systems subjected to specific hypotheses. In this paper, we considered two hypotheses that hold that a breakdown can occur during a setup activity. This breakdown can cancel (or may not cancel) the setup activities undertaken before the breakdown occurs. Hence, we propose new optimality conditions integrating the probability of breakdowns during the setup. A numerical approach is used to solve the optimality conditions obtained. A numerical example and a comparative analysis of the results for three groups of data allow us to determine the production structures and setup policies for manufacturing systems that have previously never been studied in the literature. This work can be extended to the cases of industrial systems allowing setup activities in all modes of the machine (operational or failure modes).

\section{Conflict of Interests}

The authors declare that there is no conflict of interests regarding the publication of this paper.

\section{References}

[1] S. P. Sethi and H. Zhang, "Average-cost optimal policies for an unreliable flexible multiproduct machine," The International Journal of Flexible Manufacturing Systems, vol. 11, no. 2, pp. 147157, 1999.

[2] A. Gharbi and J. P. Kenné, "Optimal production control problem in stochastic multiple-product multiple-machine manufacturing systems," IIE Transactions, vol. 35, no. 10, pp. 941-952, 2003.

[3] K. A. Francie, K. Jean-Pierre, D. Pierre, S. Victor, and P. Vladimir, "Stochastic optimal control of manufacturing systems under production-dependent failure rates," International Journal of Production Economics, vol. 150, pp. 174-187, 2014.

[4] A. Gharbi, J.-P. Kenné, and A. Hajji, "Operational level-based policies in production rate control of unreliable manufacturing systems with set-ups," International Journal of Production Research, vol. 44, no. 3, pp. 545-567, 2006.

[5] V. Polotski, J.-P. Kenné, and A. Gharbi, "Failure-prone manufacturing systems with setups: feasibility and optimality under various hypotheses about perturbations and setup interplay," International Journal of Mathematics in Operational Research, vol. 7, no. 6, pp. 681-705, 2015.

[6] C. Koulamas and G. J. Kyparisis, "Single-machine scheduling problems with past-sequence-dependent setup times," European Journal of Operational Research, vol. 187, no. 3, pp. 10451049, 2008.

[7] W. Feng, L. Zheng, and J. Li, “The robustness of scheduling policies in multi-product manufacturing systems with sequencedependent setup times and finite buffers," Computers and Industrial Engineering, vol. 63, no. 4, pp. 1145-1153, 2012.

[8] S. P. Sethi and Q. Zhang, Hierarchical Decision Making in Stochastic Manufacturing Systems, Birkhäuser, Boston, Mass, USA, 1994.

[9] H. Yan and Q. Zhang, "A numerical method in optimal production and setup scheduling of stochastic manufacturing systems," IEEE Transactions on Automatic Control, vol. 42, no. 10, pp. 1452-1455, 1997.

[10] E. K. Boukas and J. P. Kenné, Maintenance and Production Control of Manufacturing Systems with Setups, vol. 33 of Lectures in Applied Mathematics, American Mathematical Society, Providence, RI, USA, 1997.

[11] A. Hajji, A. Gharbi, and J. P. Kenne, "Production and set-up control of a failure-prone manufacturing system," International Journal of Production Research, vol. 42, no. 6, pp. 1107-1130, 2004.

[12] R. Akella and P. R. Kumar, "Optimal control of production rate in a failure prone manufacturing system," IEEE Transactions on Automatic Control, vol. 31, no. 2, pp. 116-126, 1986.

[13] H. J. Kushner and P. G. Dupuis, Numerical Methods for Stochastic Control Problems in Continuous Time, Springer, New York, NY, USA, 1992.

[14] S. X. Bai and M. Elhafsi, "Scheduling of an unreliable manufacturing system with nonresumable set-ups," Computers and Industrial Engineering, vol. 32, no. 4, pp. 909-925, 1997.

[15] G. Boothroyd, P. Dewhurst, and A. W. Knight, Product Design for Manufacture and Assembly, CRC Press, 3rd edition, 2010.

[16] A. F. Kouedeu, J. P. Kenné, P. Dejax, V. Songmene, and V. Polotski, "Production planning of a failure-prone manufacturing/remanufacturing system with production-dependent failure rates," Applied Mathematics, vol. 5, no. 10, pp. 1557-1572, 2014. 


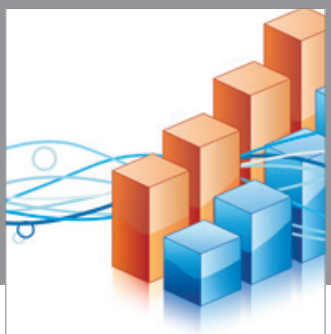

Advances in

Operations Research

vatem alat4

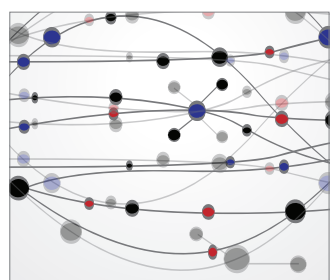

\section{The Scientific} World Journal
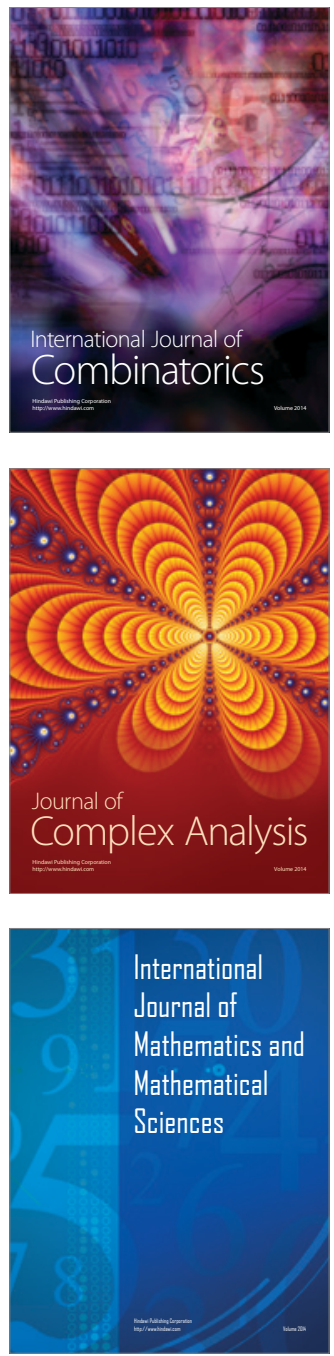
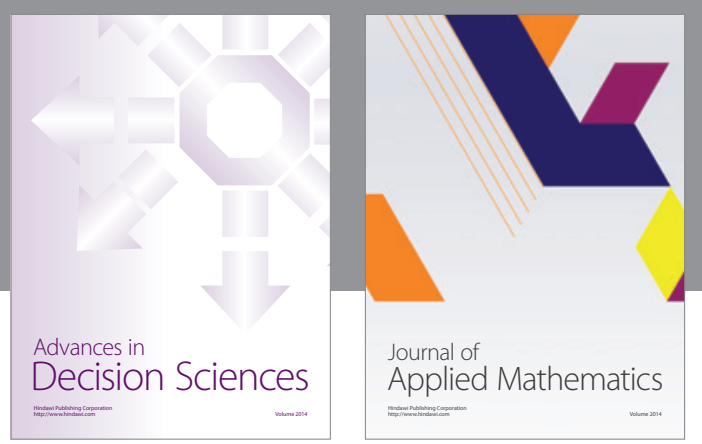

Algebra

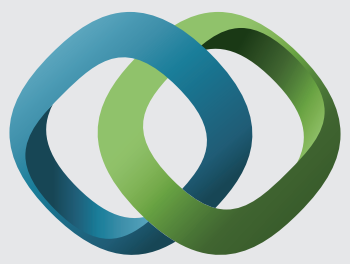

\section{Hindawi}

Submit your manuscripts at

http://www.hindawi.com
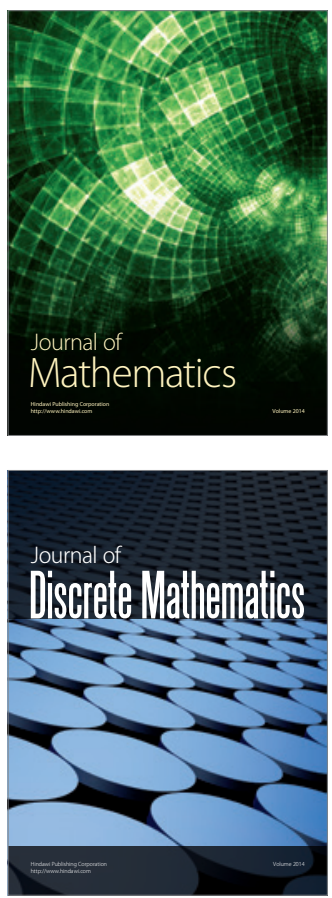

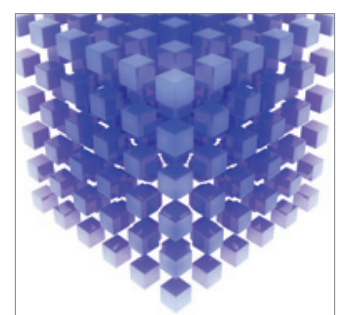

Mathematical Problems in Engineering
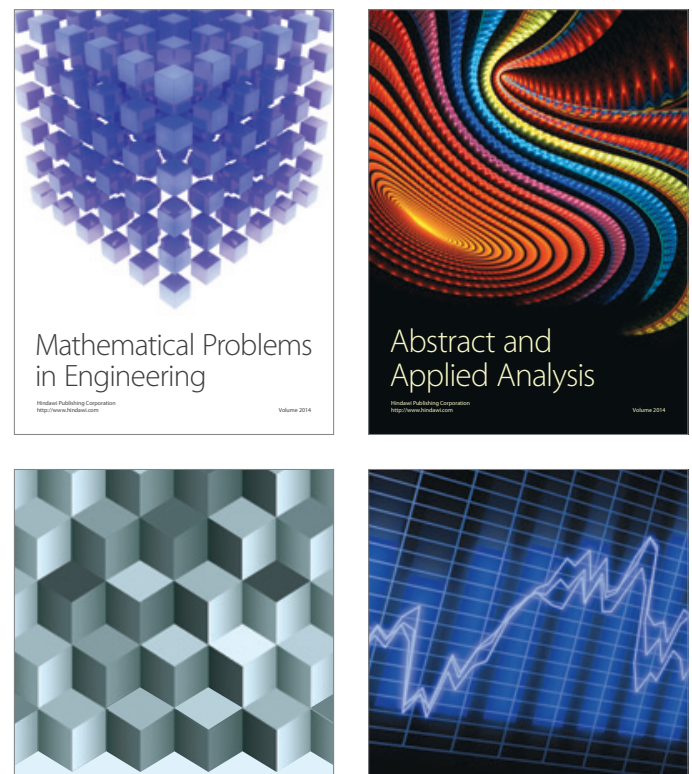

Journal of

Function Spaces

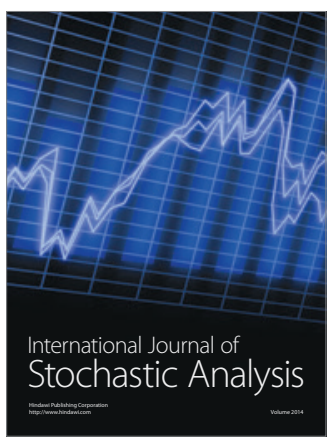

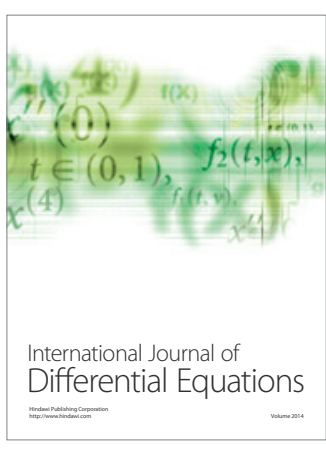
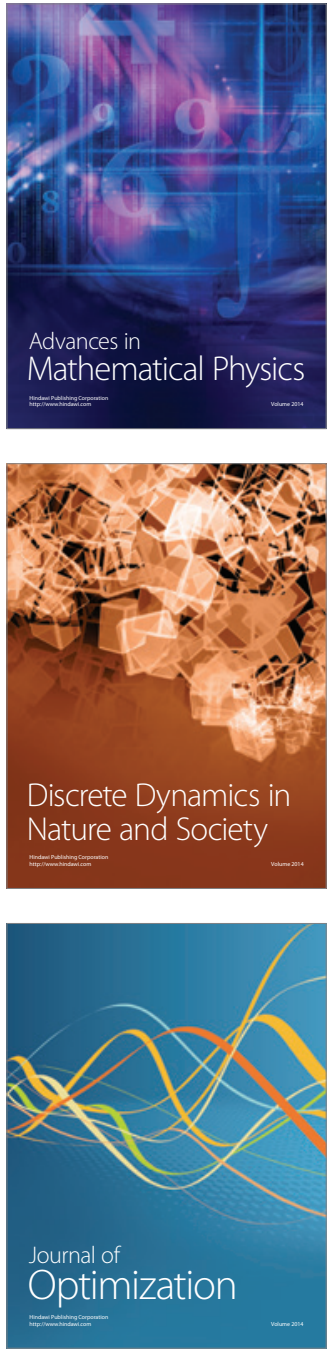